\title{
Awake Intranasal Insulin Delivery Modifies Protein Complexes and Alters Memory, Anxiety, and Olfactory Behaviors
}

\author{
David R. Marks, ${ }^{1}$ Kristal Tucker, ${ }^{1}$ Melissa A. Cavallin, ${ }^{1}$ Thomas G. Mast, ${ }^{1}$ and Debra A. Fadool ${ }^{1,2}$ \\ Department of Biological Science, ${ }^{1}$ Program in Neuroscience and ${ }^{2}$ Institute of Molecular Biophysics, The Florida State University, Tallahassee, Florida \\ 32306
}

The role of insulin pathways in olfaction is of significant interest with the widespread pathology of diabetes mellitus and its associated metabolic and neuronal comorbidities. The insulin receptor (IR) kinase is expressed at high levels in the olfactory bulb, in which it suppresses a dominant Shaker ion channel (Kv1.3) via tyrosine phosphorylation of critical N- and C-terminal residues. We optimized a $7 \mathrm{~d}$ intranasal insulin delivery (IND) in awake mice to ascertain the biochemical and behavioral effects of insulin to this brain region, given that nasal sprays for insulin have been marketed notwithstanding our knowledge of the role of Kv1.3 in olfaction, metabolism, and axon targeting. IND evoked robust phosphorylation of Kv1.3, as well as increased channel protein-protein interactions with IR and postsynaptic density 95. IND-treated mice had an increased short- and long-term object memory recognition, increased anxiolytic behavior, and an increased odor discrimination using an odor habituation protocol but only moderate change in odor threshold using a two-choice paradigm. Unlike Kv1.3 gene-targeted deletion that alters metabolism, adiposity, and axonal targeting to defined olfactory glomeruli, suppression of Kv1.3 via IND had no effect on body weight nor the size and number of M72 glomeruli or the route of its sensory axon projections. There was no evidence of altered expression of sensory neurons in the epithelium. In mice made prediabetic via diet-induced obesity, IND was no longer effective in increasing long-term object memory recognition nor increasing anxiolytic behavior, suggesting state dependency or a degree of insulin resistance related to these behaviors.

\section{Introduction}

With the ever rising incidence of diabetes mellitus, obesityinduced diabetes, and other diabetes variants, it is of critical importance to understand the role of insulin in the CNS. Most glucose transport into the CNS is not dependent on insulin, and the poor correlation of insulin receptor location and neuron energy utilization suggest that insulin has different regulatory roles in the brain over that of the periphery (Brüning et al., 2000; Hallschmid et al., 2004). Insulin in the brain acts as a neuromodulator by affecting synaptic plasticity and neurotransmitter release (for review, see Plum et al., 2005), enhances working memory, promotes neuronal survival, and regulates reproduction via the hypothalamic-pituitary axis (Brüning et al., 2000). In the olfactory bulb, insulin phosphorylates a predominant

\footnotetext{
Received March 20, 2009; accepted April 15, 2009.

This work was supported by National Institutes of Health Grants R01 DC003387, F31 DC008045, and T32 DC00044 (National Institute on Deafness and Other Communication Disorders); the Robinson Foundation, Tallahassee Memorial Hospital; a Margaret Menzel Scholarship Award, Florida State University (FSU) Biological Science; and FSU Council on Research and Creativity. We thank Dr. Leah Hanson of Health Partners, Research Foundation, for training our laboratory in intranasal delivery techniques for rodents. We thank Robert Daly, Jeff Godbey, and Michael Henderson for excellent technical assistance and routine mouse colony maintenance. We thank Jeff Godbey, Patrick Jean-Baptiste, Matthew Lundberg, Yuval Perez, Stephen Fausto, and Nathalie Munoz for assistance in behavioral phenotyping or programming. We thank Dr. Richard Bertram for reading a previous version of this manuscript.

Correspondence should be addressed to Dr. Debra A. Fadool, 319 Life Sciences, Suite 3008, Program in Neuroscience and Institute of Molecular Biophysics, The Florida State University, Tallahassee, FL 32306. E-mail: dfadool@bio.fsu.edu.

D01:10.1523/JNEUROSCI.1350-09.2009

Copyright $\odot 2009$ Society for Neuroscience $\quad$ 0270-6474/09/296734-18\$15.00/0
}

voltage-dependent potassium channel (Kv1.3) to suppress current by modifying channel mean open probability (Fadool and Levitan, 1998; Fadool et al., 2000) and activation of insulin receptor (IR) kinase blocks protein-protein interactions to modulate cell signaling with expressed adaptor proteins such as postsynaptic density 95 (PSD-95) (Marks and Fadool, 2007). Fasted mice have elevated levels of insulin in the olfactory bulb (OB), but whether insulin is locally synthesized in the brain or in other olfactory structures (Banks, 2004; Lacroix et al., 2008; Savinger et al., 2009) is not fully understood.

A majority of charged or large therapeutic agents are inhibited from entering the brain because of the blood-brain barrier. Development of neurotrophin and insulin intranasal delivery (IND) has emerged as a potential therapeutic route to reduce stroke, memory degeneration, and brain tumor development associated with neuro-AIDS, Alzheimer's, or diabetes (Kern et al., 1999; Benedict et al., 2004; González et al., 2006; Hanson and Frey, 2007; Reagan, 2007; Reger et al., 2008). IND allows rapid delivery from the nose to the CNS via an extracellular route, which does not require that the hormone selectively bind or undergo axonal transport (Dhanda et al., 2005; Hanson and Frey, 2007). Although the safety and efficacy of IND insulin was studied in terms of nasal irritation (for review, see Khafagy et al., 2007), it is surprising that less clinical attention was focused on modulation of brain function such as regulation of food intake, memory, metabolism, or synaptic plasticity (for review, see Stockhorst et al., 2004; McNay, 2007). In particular, there are gaps in our knowl- 
edge of how insulin IND might affect ion channel function/associations or whole animal behavior in relation to olfaction despite the fact that IR kinase expression and insulin binding affinity is the greatest in this brain region over all other areas of the CNS (Hill et al., 1986). Intranasally delivered molecules show highest concentrations in the $\mathrm{OB}$, providing a means to directly deliver insulin to all OB lamina (Thorne et al., 2004). The OB represents a simple, well laminated structure for which there is a wealth of functional and optical recording data of defined neural activity in response to sensory input (for review, see Shepherd, 2006). Several known targets of IR are expressed in all lamina of the OB, making it an advantageous region to study the effects of insulin modulation in situ. Moreover, the $\mathrm{OB}$ has the highest rate of blood-borne insulin uptake of all brain regions (Banks et al., 1999), suggesting it may be an important sensor of changes in metabolic and hormonal state (Apelbaum and Chaput, 2003; Aimé et al., 2007; Julliard et al., 2007). There are well designed behavioral paradigms to test olfactory function (for review, see Stevenson and Wilson, 2007; Wilson and Linster, 2008), allowing insulin-evoked physiological or biochemical changes to be studied in tandem with behavior. As a consequence, we developed a $7 \mathrm{~d}$ insulin IND paradigm in awake mice to investigate anatomical, biochemical, and behavioral changes correlated to hormone delivery to a CNS location of highest IR expression. We demonstrate that insulin IND does not damage the olfactory epithelium, alter glomerular projection, or decrease olfactory sensory neuron (OSN) numbers. Insulin evokes phosphorylation of Kv1.3 ion channel in situ, and modifies native channel protein-protein interactions. Behaviorally, insulin enhances short- and long-term object memory recognition, increases odorant discrimination after habituation, evokes anxiolytic behavior, and does not primarily affect odorant threshold.

\section{Materials and Methods}

Animals. C57BL/6 mice were housed at the Florida State University (FSU) vivarium on a $12 \mathrm{~h}$ light/dark photoperiod. Mice were individually housed after weaning at postnatal day 21 (P21) and used for experiments ranging from $\mathrm{P} 41$ to $\mathrm{P} 60$. Food and water were provided ad libitum in conventional style cages. A separate group of male C57BL/6 mice were similarly maintained but were placed on either a control chow diet $(\mathrm{Pu}-$ rina 5001) or a moderately high fat diet (MHF) (Purina D12266B; 31.8\% fat) starting at 3 months through 15 months as purchased from Research Diets. These mice were weighed weekly and used for experiments after 12 months of MHF dietary regimen.

Solutions and antisera. Human recombinant insulin was purchased from Roche and was used for intranasal delivery at a working concentration of 5 $\mu \mathrm{g} / \mu \mathrm{l}$, and for stimulation for biochemical analyses at a concentration of 10 $\mu \mathrm{g} / \mu \mathrm{l} . \alpha \mathrm{AU} 13$, a rabbit polyclonal antiserum, was generated against a 46 aa sequence, 478 MVIEEGGMNHSAFPQTPFKTGNSTATCTTNNNPNDCVNIKKIFTDV 523, representing the unique coding region of Kv1.3 between the $\mathrm{C}$ terminus and transmembrane domain 6 as initially characterized (Tucker and Fadool, 2002). This antibody was used for immunoprecipitation (IP) (3-5 $\mu \mathrm{g} / 1 \mathrm{ml}$ lysate) and Western blotting (1:1000). Olfactory marker protein (OMP) antiserum was purchased from Wako (catalog \#54410001) and used at 1:1000 for immunocytochemistry. Anti-olfactory GTPbinding protein $\left(G_{\text {olf }}\right)(1: 500)$ was a generous gift from Dr. Albert Farbman (Northwestern University, Evanston, IL), who generated the antiserum by using the same antigen as Reed's antiserum (CY coupled to KTAEDQGVDEKERREA, near the $\mathrm{N}$ terminus of rat $\mathrm{G}_{\mathrm{olf}}$ ) (Jones and Reed, 1989). Polyclonal antisera directed against the $\beta$ subunit of the human IR $\left(\mathrm{IR}_{\beta}\right.$; catalog \#MAB1139) was purchased from Millipore and has been previously characterized for cross-reactivity for cloned IR expressed in heterologous expression systems (Fadool and Levitan, 1998; Marks and Fadool, 2007) and native rodent OB tissue at 1:1000 (Fadool et al., 2000; Marks and Fadool, 2007). Anti-phosphotyrosine (4G10) (catalog \#05-1050) was purchased from Millipore and has been well characterized for detection of Kv1.3 phosphorylation at 1:1000 (Colley et al., 2004, 2007; Fadool et al., 2004; Marks and Fadool, 2007). Insulin antisera (catalog \#sc-9168) was purchased from Santa Cruz Biotechnology and was used for peroxidase-based immunolabeling at 1:200. Monoclonal $\beta$-actin (catalog \#A2228) antisera was purchased from Sigma-Aldrich and used at 1:800 for Western blots as a secondary control for equivalent protein expression. Kv1.3 (catalog \#AB5178a), PSD-95 (catalog \#MAB1596), and Pan Homer (catalog \#AB5875) antisera were purchased from Millipore, and used at 1:200, 1:500, and 1:1000, respectively.

The three buffers $(\mathrm{A}-\mathrm{C})$ used to visualize $\beta$-galactosidase reaction product contained the following: buffer A, $0.1 \mathrm{M}$ phosphate buffer, $2 \mathrm{mM}$ $\mathrm{MgCl}_{2}$, and $5 \mathrm{~mm}$ EGTA; buffer B, $0.1 \mathrm{M}$ phosphate buffer, $2 \mathrm{~mm} \mathrm{MgCl}_{2}$, $0.01 \%$ sodium deoxycholate, and $0.02 \%$ Nonidet P40; buffer C, buffer B with $5 \mathrm{~mm}$ potassium ferricyanide, $5 \mathrm{~mm}$ potassium ferrocyanide, and $600 \mu \mathrm{g} / \mathrm{ml} \mathrm{X}$-gal. X-gal was purchased from Research Products International. All other solutions for cell lysis, homogenization, immunocytochemistry, and protein biochemistry were used as described fully previously (Fadool et al., 2000; Cook and Fadool, 2002; Biju et al., 2008).

Intranasal insulin delivery and tissue processing. There are two major routes for noninvasive insulin delivery: pulmonary (inhaled) and intranasal (IND). In pulmonary routes of administration, insulin is absorbed into the pulmonary vasculature to affect systemic glucose levels (Hollander, 2007). In IND routes of administration, insulin can be paired with a carrier to enhance nasal absorption into the vasculature of the main olfactory epithelium (MOE) to affect systemic glucose levels or insulin can be unpaired and delivered either as an aerosol or liquid to gain entry into the CNS via extracellular spaces in the cribriform plate. In IND routes of administration (unpaired), aerosolized insulin in humans (Hallschmid et al., 2008) and insulin solutions in animal models has proven to use an identical route to deliver the hormone into rostral brain structures without reaching the blood serum that would elicit systemic side effects. We modified IND delivery in mice that was originally piloted for Sprague Dawley rats by Thorne et al. (2004). In this, and subsequent experiments using animals, animal protocols were conducted per Florida State University Laboratory Animal Resources and American Veterinary Medical Association (AVMA)-approved methods. For anesthetized delivery, P45-P55 C57BL/6 mice were anesthetized with $60 \mathrm{mg} / \mathrm{kg}$ sodium pentobarbitol diluted in saline (full dose). Up to two maintenance halfdoses were given as needed. A meniscus of insulin containing solution was formed using a standard P10 pipette tip and presented to the naris of the anesthetized mouse while in a supine position with airway passages supported open using a gauze roll under the neck. Two microliter drops of $3 \mu \mathrm{g} / \mu \mathrm{l}$ insulin or PBS vehicle were inhaled into alternating nares every $2 \mathrm{~min}$ for $30 \mathrm{~min}$ total. Ten minutes after the last intranasal dose, mice were killed via an overdose of sodium pentobarbitol and decapitated. Olfactory bulbs were dissected out, homogenized, and subjected to immunoprecipitation as described above.

For awake intranasal insulin delivery, P41-P51 mice were weighed and given an identifying mark (hair shaving) before the first treatment. For delivery, mice were hand-restrained, placed in a supine position, and given three $10 \mu \mathrm{l}$ drops of $5 \mu \mathrm{g} / \mu \mathrm{l}$ insulin, PBS, or $5 \mu \mathrm{g} / \mu \mathrm{l}$ insulin heated at $95^{\circ} \mathrm{C}$ for $15 \mathrm{~min}$ (boiled) into both nares simultaneously. A meniscus of solution was similarly formed and presented for inhalation by the awake mouse as was described above for the anesthetized condition. Mice were given an extra $10 \mu \mathrm{l}$ treatment drop if the subject forcibly ejected or sneezed out solution. Mice were held supine for 5-10 s after delivery to ensure all fluid was inhaled. Because of the viscous nature of 5 $\mu \mathrm{g} / \mu \mathrm{l}$ insulin solution, it was impossible to deliver the meniscus to a single naris effectively; hence all awake treatments were administered to both nares. It was previously shown that intranasally delivered insulinlike growth factor reaches the OB with an efficiency of $0.11 \%$ (Thorne et al., 2004). Based on those calculations and the equivalent molecular weight of insulin, it is estimated that $9 \mathrm{~nm}$ insulin is the effective dose of insulin reaching the OB. This treatment was repeated for $\sim 30 \mathrm{~min}$, or until all mice had received 90 total $\mu \mathrm{l}$ of solution. This protocol was repeated twice daily at 7:00 A.M. and 7:00 P.M. for 5 d. On days 6 and 7, mice continued their insulin treatment regimen and were subjected to behavioral testing $\sim 3 \mathrm{~h}$ after their morning dose. On the evening of day 7, mice were given their last treatment at 7:00 P.M. and killed $3 \mathrm{~h}$ later to 
ensure that biochemical analyses were performed using the same pretreatment increment as the behavior tests. Mice were killed via $\mathrm{CO}_{2}$ inhalation followed by decapitation. The olfactory bulbs were dissected out and prepared for immunohistochemistry or immunoprecipitation. The remainder of the nose was immersion fixed in $4 \%$ paraformaldehyde for $24 \mathrm{~h}$, and then placed in a vacuum chamber for $2 \mathrm{~h}$ to ensure complete fixation inside the nares. Noses were decalcified in $0.5 \mathrm{M}$ EDTA for 3-4 d, and then cryoprotected in a series of 10, 20, 30\% sucrose PBS. Approximately $4 \mathrm{ml}$ of embedding medium was added and the tissue was placed in a vacuum chamber for $2 \mathrm{~h}$. Tissue was frozen, and 16-20 $\mu \mathrm{m}$ coronal sections were cut on a cryostat and stored at $-20^{\circ} \mathrm{C}$ for later use.

Peripheral blood glucose concentration was determined for animals receiving awake intranasal delivery by sampling tail blood acquired at time $0,5,30,60$, and $90 \mathrm{~min}$ after IND treatment and monitoring glucose levels with a glucose meter (Ascensia Contour; Bayer Healthcare LLC). Quantified trunk blood was determined to have consistently lower blood glucose concentration than that of tail sampling ( $\sim 40 \mathrm{mg} / \mathrm{dl})$; therefore, most measurements were uniformly taken from the tail to acquire a paired or repeated blood sampling. It was not possible to sample enough blood from a tail for ELISA; therefore, isolated serum from trunk bleeds had to be used on harvest to determine blood insulin concentrations. Blood insulin concentration after chronic IND was determined via ELISA technique per manufacturer's specifications (Ultrasensitive Mouse Insulin kit \#10-1150-01; Mercodia).

Protein chemistry. Harvested OBs were homogenized in ice-cold lysis buffer including protease and phosphatase inhibitors as described previously (Fadool et al., 2000). Since OBs were harvested from single animals and not pooled, homogenates were rotated at $4^{\circ} \mathrm{C}$ for $4-6 \mathrm{~h}$ to increase protein extraction. The lysates were then clarified by centrifugation at $14,000 \times g$ for $30 \mathrm{~min}$ at $4^{\circ} \mathrm{C}$, and precleared for $2 \mathrm{~h}$ with $3 \mathrm{mg} / \mathrm{ml}$ protein A-Sepharose (GE Healthcare). The protein of interest was immunoprecipitated from the cleared lysates by incubation overnight with $5 \mu \mathrm{g} / \mathrm{ml}$ specific antibody at $4^{\circ} \mathrm{C}$. The immunoprecipitates were then washed four times with wash buffer, and proteins were separated on $10 \%$ acrylamide gels by SDS-PAGE, followed by electrotransfer to nitrocellulose membranes. The nitrocellulose membranes were blocked with $5 \%$ nonfat milk or $2 \%$ bovine serum albumin (TBST-Block; Sigma-Aldrich) and incubated overnight at $4^{\circ} \mathrm{C}$ with primary antibody. Membranes were then incubated with species-specific horseradish peroxidase (HRP)conjugated secondary antiserum diluted in TBST for $90 \mathrm{~min}$ at room temperature ( $\mathrm{rt}$ ). Labeled proteins were visualized by enhanced chemiluminesence (ECL) (GE Healthcare) and band pixel density was quantified using scanning densitometry as previously described (Cook and $\mathrm{Fa}$ dool, 2002; Marks and Fadool, 2007).

Behavior. After $5 \mathrm{~d}$ of IND, mice were tested for general anosmia and short-term $(1 \mathrm{~h})$ and long-term $(24 \mathrm{~h})$ object memory as previously performed and analyzed (Jeon et al., 2003; Fadool et al., 2004). These same mice were also subjected to odor habituation trials (Fletcher and Wilson, 2002; Fadool et al., 2004) and light/dark box (LDB) testing (Bourin and Hascoët, 2003). To test for discrimination of a second odor after the habituation to a first odor, odor mixtures (peppermint, geranyl acetate) or single odorant alcohols differing by number of carbon atoms (alcohol C9/C10) were diluted 1:100 in mineral oil or water and applied to a cotton swab. The cotton swab was introduced to the mouse through the top of the testing cage and time of active investigation/smelling of the odor was recorded over a $1 \mathrm{~min}$ trial period. Mice were habituated to the first odor of an odor pair combination by repeat stimulation with the odor saturated swab for seven trials using 1 min resting intervals. On the eighth trial, the second odor of the odor pair was presented and time of exploration was scored. All recorded times were normalized and compared with the animal's original exploration time before habituation to minimize the between-animal variance. For light/dark box testing, a rat cage $(29.2 \times 19.1 \times 12.7 \mathrm{~cm})$ was modified as follows: A black cardboard divider was cut to the exact width and height of the cage and a $7 \times 7 \mathrm{~cm}$ square opening was cut in the middle on the bottom edge. The divider was placed in the middle of the cage, creating two equally sized compartments. One side of the cage was painted black (dark), and the other side was painted white (light). Another black cardboard piece was cut for the top of the dark chamber and fitted tightly in place, ensuring no outside light entered the dark chamber. A $60 \mathrm{~W}$ light bulb was then hung $70 \mathrm{~cm}$ directly over the center of the white chamber. For testing, mice were placed in the center of the light chamber and a timer was started at the time of release. The time period from release to mouse entrance into the dark chamber (latency) was measured. Entrance into a chamber was defined as all four paws of the mouse crossing into that chamber. The number of times a mouse crossed between chambers was also scored (transitions), and the total time the mouse spent in the light chamber was measured. The test lasted for $5 \mathrm{~min}(300 \mathrm{~s})$, and the time spent in the dark chamber was calculated by subtracting total time in the light chamber from $300 \mathrm{~s}$.

A separate set of IND-treated mice were subjected to the marbleburying (MB) test (Nicolas et al., 2006) and the elevated plus maze (EPM) (Stowe et al., 2005) as parallel tests for anxiety. In these trials, mice were prescreened on separate days for each anxiety test, treated for $5 \mathrm{~d}$ with insulin or PBS vehicle, and then retested for each anxiety test on the sixth or seventh day of IND treatment, respectively. For marble-burying trials, mice were habituated for $15 \mathrm{~min}$ to a rat cage $(29.2 \times 19.1 \times 12.7$ $\mathrm{cm}$ ) filled with $5 \mathrm{~cm}$ of bedding material. Eighteen evenly placed marbles $(6 \times 3$ array) were then arranged in the test cage. At the end of a $45 \mathrm{~min}$ test period, the mouse was returned to its home cage and the fraction of buried marbles was scored. A marble had to be buried at least two-thirds of the way with bedding before it was considered as buried. Although it is not exactly understood why the mice bury the marbles, it has been shown the drugs that induce anxiolytic activity in humans, also decrease the number of marbles buried in this test (Nicolas et al., 2006). The EPM was constructed by Columbus Instruments and has been validated for successful use in rats, mice, and voles (Pellow et al., 1985; Lister, 1987; Stowe et al., 2005). The EPM was comprised of two open arms $[35 \mathrm{~cm}(\mathrm{~L}) \times 6.5$ $\mathrm{cm}(\mathrm{W})]$ and two closed arms $[35 \mathrm{~cm}(\mathrm{~L}) \times 5 \mathrm{~cm}(\mathrm{~W}) \times 15 \mathrm{~cm}(\mathrm{H})]$ that crossed in the middle and was elevated $45 \mathrm{~cm}$ off the ground. Mice were individually placed on the cross intersection of the EPM facing an open arm and scored by videocinematography for 5 min under standard lighting conditions. Postexperiment analysis was assisted by home-written software (Yuval Perez, FSU Computer Science, Tallahassee, FL) that scored numbers of entries into open or closed arms, time spent in each arm or in the center, and number of falls. An entry into an arm was counted only when all four paws of an animal crossed from the center panel onto the arm. The maze was wiped with $70 \%$ ethanol between trials.

A separate group of mice were used in a two-choice paradigm to ascertain odorant threshold as previously described (Colacicco et al., 2002; Fadool et al., 2004). During the apparatus habituation period and acquisition phase in which the mouse is trained to make a decision (dig) to uncover a baited reward (honey-flavored cereal) under an odor-scented litter compartment, the animal is fasted to $75-85 \%$ of its body weight (days 1-3). Once mice were trained near 100\% efficiency to dig for the food reward by odorant pairing, odorant threshold testing began (days $4-6)$. For each daily test session, mice were progressively tested on sequentially lower dilutions that were prepared in 10-fold dilution step increments. A test of a given dilution consisted of four to eight trials. If a mouse responded with $90-100 \%$ for correct decisions, it was tested on the next lower dilution. Since mice only had the capacity to stay attentive to the task for $30-45 \mathrm{~min}(\sim 15$ trials), the lowest dilution at which $100 \%$ correct decisions was made was resumed on the next day. If the mouse responded incorrectly (60-80\% correct decisions), it was retested twice with the previous stronger dilution. Once mice reached a dilution at which they scored a combined average of $80 \%$ correct choice, insulin treatment was started. Mice received either insulin (intact hormone) or boiled insulin (denatured hormone) at 7:00 P.M. and 7:00 A.M. in order that behavioral testing could be performed 3-4 h after treatment in a room isolated from external noise. During the $5 \mathrm{~d}$ IND treatment period (days 7-11 overall), mice were not behaviorally tested. Mouse weights were also allowed to increase at the start of insulin treatment to protect against a trend of $4-5 \%$ body weight loss with chronic treatment. Mouse weights were carefully monitored and slowly lowered via food restriction over the course of intranasal treatment back down to $75-85 \%$ of original body weight. On the sixth day of IND treatment (day 12 overall), mice were started at the successful odor dilution, and testing to determine 
odorant threshold was resumed. Odorant threshold was determined at $50 \%$ correct decisions or retrieval of reward by chance alone. This behavioral paradigm was designed based on modification of protocols described by Yee and Wysocki (2001), Colacicco et al. (2002), and the Hyde Laboratory (Schering Plough Research Institute, Kenilworth, NJ).

A separate group of male mice were placed on a control or matched MHF diet to test for state dependency of IND-related channel phosphorylation and behaviors. The method of IND (insulin or PBS vehicle) was identical with that previously described with the exception of the adult age of the mouse at onset of treatment (16 months) required to accommodate diet-induced obesity. Mice were provided either control Purina or MHF diet ad libitum at 3 months of age for 55 weeks. Animals were weighed weekly and tail blood was sampled 1 week before IND treatment to confirm induction of hyperglycemia by glucose meter. Behavior phenotyping was conducted using a paired metric, before and subsequent to IND treatment, to include $24 \mathrm{~h}$ object memory, LDB, EPM, and marbleburying trials. IND treatment interval (without intervening behavioral testing) remained a $5 \mathrm{~d}$ window, and total IND treatment was extended to $9 \mathrm{~d}$ overall to complete the battery of post-IND treatment behavioral tasks. Mice were phenotyped for LDB and the first day of object memory on sixth day of IND, second day of object memory on seventh day of IND, marble burying on eighth day of IND, and EPM on ninth day of IND. This paradigm mostly limited the animal testing interval to $<15$ min per day to minimize stress/handling. Tail blood and olfactory bulb tissue were harvested $3 \mathrm{~h}$ after final IND treatment on the evening of day 9.

$X$-Gal staining. M72-IRES-tau-LacZ mice were generated previously via placement of an internal ribosome entry site (IRES) directing the translation of tau:lacZ fusion protein immediately downstream of the M72 odorant receptor (OR) stop codon (Mombaerts et al., 1996; Zheng et al., 2000). These mice were a generous gift from Dr. Peter Mombaerts (Max Planck Institute of Biophysics, Frankfurt am Main, Germany). OSNs of these mice that express these modified M72 receptors can be visualized by histological staining for $\beta$-galactosidase activity along with the odorant receptor (Mombaerts et al., 1996; Zheng et al., 2000). Mice were killed with an overdose of sodium pentobarbital and perfused with $4 \%$ paraformaldehyde per Florida State University Laboratory Animal Resources and AVMA-approved methods. Heads were decalcified in 0.3 м EDTA for $48 \mathrm{~h}$ at $4^{\circ} \mathrm{C}$. Both the nasal epithelium and olfactory bulbs were exposed and rinsed in PBS. A total of 16 animals, four per IND treatment (insulin, PBS, boiled insulin, and untreated) were processed for whole-mount staining (Biju et al., 2008). Briefly, tissue preparations were washed with buffer A for $5 \mathrm{~min}$ and then again for $25 \mathrm{~min}$ at rt. Tissues were then twice incubated with buffer B for 5 min each, followed by a $6 \mathrm{~h}$ to overnight incubation in buffer $\mathrm{C}$ at $\mathrm{rt}$. Whole mounts were examined with a Leica MZ FLIII stereomicroscope and images were acquired with an Olympus DP10 digital camera. After whole-mount imaging, tissue was cryoprotected in a series of $10,20,30 \%$ sucrose in PBS, and coronally sectioned at $16 \mu \mathrm{m}$ on a cryostat. Sections were washed with buffer A for $5 \mathrm{~min}$ and then again for $25 \mathrm{~min}$ at rt. Sections were then twice incubated with buffer B for 5 min each, followed by a $6 \mathrm{~h}$ to overnight incubation in buffer $\mathrm{C}$ at rt. Cryosections were counterstained with neutral red after the above $\mathrm{X}$-gal processing to visualize targets of projections and number and distribution of M72-expressing OSNs by light photomicroscopy (Zeiss Axiovert S 100). Manual counts of positively identified OR-expressing OSNs were statistically compared across groups using a one-way ANOVA with a Student-Newman-Keuls follow-up test ( $\alpha=0.05$ ).

\section{Results}

Intranasal insulin delivery to anesthetized and awake animals significantly increases Kv1.3 tyrosine phosphorylation

Kv1.3 is a target for tyrosine phosphorylation by the insulin receptor kinase, which has been demonstrated in HEK 293 cells and cultured OB neurons (Fadool and Levitan, 1998; Fadool et al., 2000; Marks and Fadool, 2007). Although these are excellent paradigms to study protein-protein interactions, they do not accurately represent the native environment of the olfactory bulb. To demonstrate that the insulin receptor kinase phosphorylates Kv1.3 in situ, 10 anesthetized animals (5 hormone and 5 PBS vehicle) received IND as described in Materials and Methods. Animals were killed per National Institutes of Health-approved methods and OBs were quickly harvested. Kv1.3 was immunoprecipitated from the clarified OB lysate, separated by SDSPAGE, and probed with $\alpha 4 \mathrm{G} 10$, an antiserum recognizing phosphotyrosine. As shown in Figure $1 A$, insulin-treated animals (I+) show a significant increase in Kv1.3 phosphorylation (IP, gel lanes 1-2) but no change in channel protein expression (lysate, gel lanes 3-4). These data were quantified by pixel densitometry and statistically compared in the bar graph below the Western blot (Fig. 1C) (Kv1.3 Phosphorylation Anesth, Student's $t$ test, $\alpha=0.05)$. In this and subsequent analyses, plotted pixel values for the immunoprecipitated Kv1.3 protein were normalized within blot to that of the vehicle alone condition $(\mathrm{V})$ to eliminate differences in ECL exposure times between autoradiographs.

The effect of single-treatment insulin IND was next compared with a chronic IND paradigm using awake animals as described in Materials and Methods. The frequency of insulin delivery was optimized to best mimic clinical insulin nasal sprays previously marketed (for review, see Barnett, 2004; Dunn and Curran, 2006a,b). Mice were given intranasal insulin (I+), PBS (V), or boiled insulin (B) twice a day for $5 \mathrm{~d}$ before being subjected to behavioral tests on the sixth and seventh days of treatment. After the mice were killed on day 7, Kv1.3 was immunoprecipitated from the clarified OB lysate, separated via SDS-PAGE, and probed with $\alpha 4 \mathrm{G} 10$, an antiserum recognizing phosphotyrosine. A total of 14 animals in each treatment group were used for biochemistry to ascertain the phosphorylation state of the Kv1.3 channel. The data demonstrate that there is a 2.5 -fold increase in Kv1.3 tyrosine phosphorylation after $7 \mathrm{~d}$ of intranasal insulin treatment (Fig. 1 B, C) (Kv1.3 Phosphorylation Awake, Student's $t$ test, $\alpha=0.05$ ). This effect is specific to insulin ( $\mathrm{I}+$ ) because the PBS vehicle (V) or denatured hormone (B) evoke no increase in Kv1.3 tyrosine phosphorylation. Thus, chronic insulin IND treatment evokes robust phosphorylation of Kv1.3 in situ. Insulin (I+) did not alter expression of Kv1.3 channel protein compared with that of PBS vehicle-treated animals (V) as demonstrated in OB lysates probed with $\alpha \mathrm{Kv} 1.3$ (input) or stripped and reprobed with $\alpha \beta$-actin (additional control) (Fig. 1D). Albeit not the targeted focus of our study, we confirmed that awake insulin IND treatment extended beyond the delivery range of the $\mathrm{OB}$ as reported by others (Thorne et al., 2004; Dhanda et al., 2005). We were able to detect increased phosphorylation of IR kinase in the hippocampus using the same paradigm above (data not shown). After insulin IND compared with that of PBS vehicle, there was a 1.3 -fold increase in tyrosine phosphorylation of the IR in the hippocampus detected via immunoprecipitation of tyrosine phosphorylated proteins $(\alpha 4 \mathrm{G} 10)$ and probing with $\alpha$ IR kinase-analogous to biochemical strategies performed above in the OB (not significantly different, Student's $t$ test, $\alpha=0.05$ ).

\section{Scaffolding of ion channels, receptor-linked tyrosine kinases, and adaptor proteins is altered by chronic insulin IND treatment}

Previous work has demonstrated a PSD-95-dependent association between Kv1.3 and IR that is enhanced by insulin-evoked channel tyrosine phosphorylation (Marks and Fadool, 2007). Phosphorylation is known to provide additional docking sites on channels for adapter proteins; hence, changes in known proteinprotein interactions with Kv1.3 were examined. Kv1.3 was im- 
munoprecipitated from the OB lysates of IND-treated animals as described in Materials and Methods, and immunoprecipitated Kv1.3 channel was separated via SDS-PAGE and probed for PSD-95 and IR. Additionally, IR was immunoprecipitated from a subset of treated animals, separated via SDS-PAGE, and probed with anti-phosphotyrosine ( $\alpha 4 \mathrm{G} 10)$ to confirm the extent of receptor activation and autophosphorylation (Fig. 2A). Figure 2, $B$ and $D$, demonstrates that insulin IND treatment increased PSD-95 coimmunoprecipitation with Kv1.3 and IR approximately fourfold to fivefold. Insulin IND treatment also markedly increased the amount of IR that coimmunoprecipitated with Kv1.3 (Fig. 2C). The increases in protein-protein interaction with Kv1.3 are attributed specifically to insulin because PBS or the denatured hormone fails to evoke autophosphorylation of IR kinase as quantified in Figure $2 E$. Thus, insulin IND treatment evokes activation of IR in situ and enhances the scaffolding association of Kv1.3, IR, and PSD-95 protein complexes.

Gene-targeted deletion of Kv1.3 evokes changes in expression of a wide variety of receptor-linked tyrosine kinases (RTKs) and adaptor proteins (Fadool et al., 2004). Insulin-evoked Kv1.3 current suppression in situ could likely mimic the state of the null animals; hence the protein expression of various RTKs and adaptor proteins was analyzed. OB whole-cell lysates were separated by SDS-PAGE, electrotransferred to nitrocellulose, which was then probed with Kv1.3, IR, PSD-95, TrkB, and Pan Homer antisera to determine whether insulin treatment evoked changes in protein expression levels. These lysates were acquired as matched aliquots before immunoprecipitation as above (input) (Fig. $2 \mathrm{~A}$, top panels) and were run in the same electrophoretic front as the IPs but on different gels. Controls included strip of the IP and reprobe with $\alpha \mathrm{Kv} 1.3$ or $\alpha \mathrm{IR}$ as in Figure 1 (data not shown) and probe of lysates with $\alpha \mathrm{Kv} 1.3$, $\alpha \mathrm{IR}$, or $\alpha \beta$-actin (Fig. $2 A$, bottom panels) to quantify lack of expression changes with treatment. Kv1.3, IR, TrkB (data not shown), and PSD-95 expression did not change with insulin IND treatment; however, the expression of the $54 \mathrm{kDa}$ isoform of Homer increased by $50 \%$ (Fig. $2 \mathrm{~A}$, last panel). Thus, chronic insulin IND treatment did not affect the expression of the majority of proteins examined, except for that of a Homer isoform.

\section{Chronic insulin IND treatment does not damage the olfactory} epithelium or cause general anosmia

The repeated delivery of fluid into the nares raised the possibility that damage to the olfactory epithelium could occur despite the
B

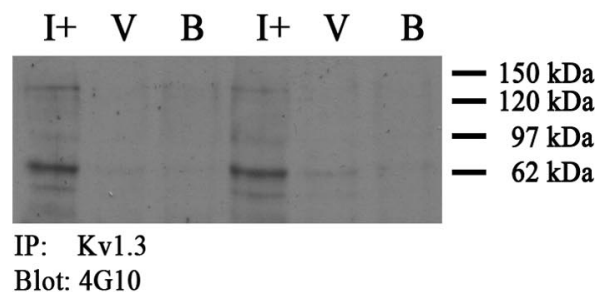

Blot: 4G10
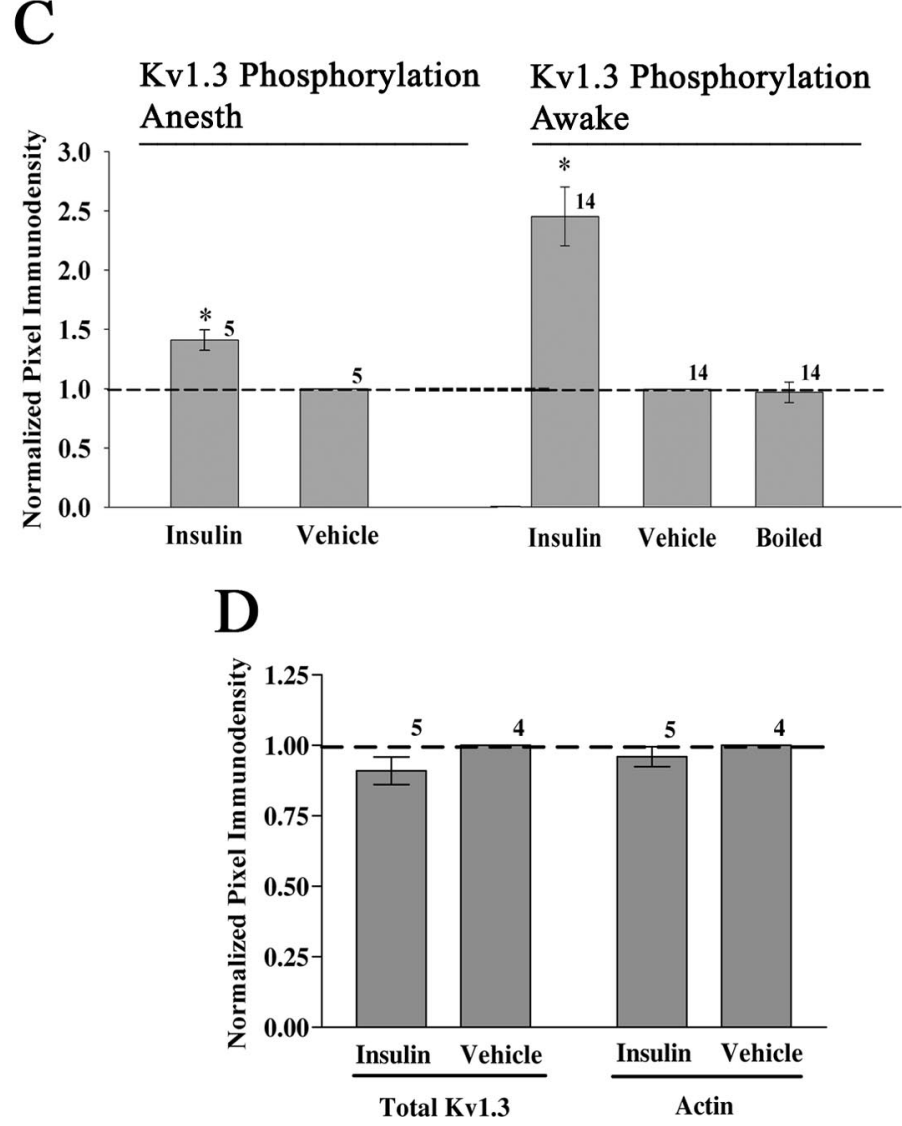

Figure 1. Intranasal insulin evokes Kv1.3 tyrosine phosphorylation in anesthetized and awake animals. Representative Western blots and quantitative scanning densitometry summary histograms of Kv1.3 tyrosine phosphorylation under anesthetized (Kv1.3 Phosphorylation Anesth) (A, $\boldsymbol{C}$ or awake (Kv1.3 Phosphorylation Awake) ( $\boldsymbol{B}, \boldsymbol{C})$ states. Under both conditions, mice were intranasally administered insulin (I+), PBS vehicle (V), or boiled insulin (B) as indicated. Details of delivery and animal handling can be found in the methods. OBs were harvested, and Kv1.3 channel was immunoprecipitated from clarified OB lysates (IP. Kv1.3), separated via SDS-PAGE, and probed with anti-phosphotyrosine (blot: 4G10). OB lysates (lysate) were run in tandem with immunoprecipitated samples to demonstrate equal Kv1.3 expression and input (blot Kv1.3). C, Summary bar graph is the mean ( \pm SEM) pixel density of the phosphorylated Kv1.3 band as normalized to the vehicle (dashed line, ratio of 1.0). D, Summary bar graph is the mean ( \pm SEM) pixel density of two controls, total Kv1.3 channel (input) or actin as quantified from the lysates and similarly normalized to the vehicle. *Significantly different from vehicle by Student's $t$ test, $\alpha=0.05$, arc-sin transformation for percentage data. Sample sizes are as indicated.

short duration of our 5-7 d treatment. To address this, noses from IND-treated animals were processed as described in Materials and Methods. Sections from insulin, PBS, boiled, and untreated animals were double labeled for OMP and $\mathrm{G}_{\text {olf }}$ (Hartman and Margolis, 1975; Jones and Reed, 1989). Sections were then visualized on a confocal microscope to ascertain the morphology of the nasal epithelium and the OSNs. Figure 3 demonstrates that there were no gross morphological changes nor outward damage visible for any of the groups examined. $G_{\text {olf }}$ expression overlapped with OMP signal in the fine ciliary layer (Fig. 3D, $H, L, P$ ), 
A

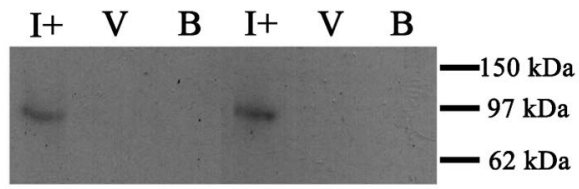

IP: Kv1.3

Blot: PSD-95

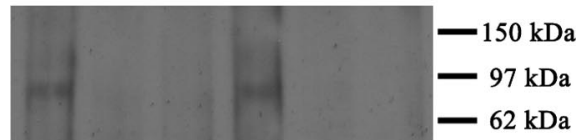

IP: Kv1.3

Blot: IR

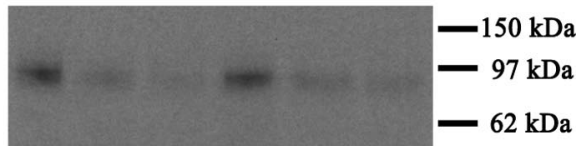

IP: IR

Blot: PSD-95

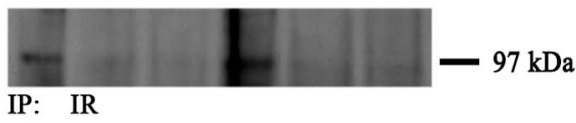

Blot: 4G10

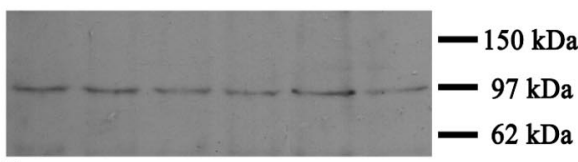

Lysate

Blot: IR

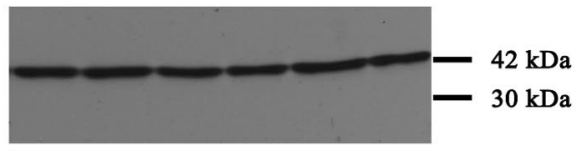

Lysate

Blot: Actin

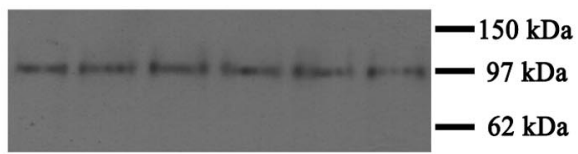

Lysate

Blot: PSD-95

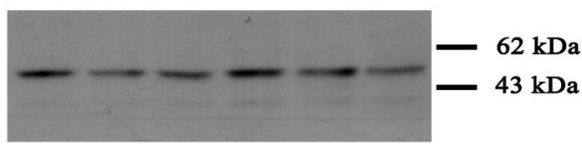

Lysate

Blot: Pan Homer

Figure 2. Insulin IND treatment enhances Kv1.3 protein-protein interactions with PSD-95 and IR. $A$, Representative Western blots and quantitative scanning densitometry summary histograms $(\boldsymbol{B}-\boldsymbol{E})$ of channel or kinase phosphorylation or coimmunoprecipitations as noted. Data represent awake IND delivery; protein biochemistry protocols, analysis, and applied statistics as in Figure 1. IR, Insulin receptor kinase. For each SDS-PAGE/Western blot example, two sets of awake IND treatment groups are shown to demonstrate accuracy and reproducibility across experiments. Labeling for actin in the input (lysate, blot: actin) is also demonstrated as an additional control. Sample sizes are as indicated.

zand OSN cell bodies are clearly visible in an intact epithelium visualized with $4^{\prime}, 6^{\prime}$-diamidino-2-phenylindole (DAPI)-labeled nuclei (Fig. 3C, $G, K, O$ ). Additionally, sections from each treatment group were stained with a simple trichromatic acidic tolu- idine blue/neutral red/fast green mixture to demonstrate excellent tissue structure and histology (data not shown).

The abundance of OSNs is decreased in mice with Kv1.3-gene-targeted deletion (Biju et al., 2008), therefore, we wondered whether insulin-evoked Kv1.3 suppression could result in the same anatomical phenotype. Images were taken from two ectoturbinates and two endoturbinates on each epithelium section at various depths along the rostral-caudal axis. The number of OMP-positive cells per $300 \mu \mathrm{m}$ of epithelium was counted and compared across turbinates of all IND treatment groups using a two-way ANOVA with a StudentNewman-Keuls test $(\alpha=0.05)$ (Fig. 3Q). The data demonstrate that there was no significant difference in the number of olfactory sensory neurons per $300 \mu \mathrm{m}$ of epithelium in any of the four turbinates examined nor across IND treatment groups.

Another possibility was that, although the structure and morphology of the olfactory epithelium remained intact, the functional cellular transduction machinery in the OSNs or general olfactory processing might be damaged and cause general anosmia in the animal. To address this, a test for general anosmia was performed as described in Materials and Methods. Figure $3 R$ demonstrates that insulin, PBS, and boiled insulin IND treatment groups show similar retrieval times of a food odor (cracker) over that of a matched, unscented object (marble) when compared with that of untreated mice. Thus, repeated IND treatment does not damage the olfactory epithelium, does not decrease the number of OSNs, nor does it elicit general anosmia.

Chronic insulin IND treatment does not affect glomerular position or number of olfactory sensory neurons expressing the M72 odor receptor

Gene-targeted deletion of Kv1.3 evokes a decrease in glomerular size, an increase in glomerular number, and the appearance of supernumerary glomerular projections (Fadool et al., 2004; Biju et al., 2008). Because insulin-evoked tyrosine phosphorylation of Kv1.3 suppresses channel current (Fadool and Levitan, 1998; Fadool et al., 2000; Marks and Fadool, 2007), it is possible that chronic IND treatment could produce similar axonal targeting defects as observed in the Kv1.3 gene-targeted deletion. To address this, M72 (IRES) Tau-LacZ transgenic mice were IND-treated with insulin, PBS, or boiled insulin for $7 \mathrm{~d}$. The use of targeted mutagenesis in the germline of mice affords an advantage over human models because the translation of a single class of odorant receptor (in these mice, the M72 
odorant receptor) is linked with tauLacZ to allow direct visualization of the genetically identified sensory axons and their projections into the brain (Mombaerts et al., 1996). Therefore, this technology permitted the monitoring of select glomerular synaptic targets and their molecularly identified presynaptic OSNs. There were four mice in each treatment group, along with four other mice left untreated as a standard measurement and control. Mice were killed and processed for wholemount X-gal staining (Biju et al., 2008). Images of whole mounts were taken in the transverse plane to determine the location and number of M72 glomeruli. The images demonstrate that there is no qualitative difference across treatment groups in M72 glomerulus location, intensity of axonal projections, nor refinement of projections (absence of supernumerary glomeruli) (Fig. 4A-D). In each group, there were two M72 glomeruli per olfactory bulb, one lateral and one medial. All lateral glomeruli were posterior to a rostral-caudal axis midline, and at least $1 \mathrm{~mm}$ from the sagittal midline of a single olfactory bulb. The medial glomeruli can be observed by gently spreading the area between each olfactory bulb $\sim 1 \mathrm{~mm}$ and were in the same location in all groups.

Gene-targeted deletion of Kv1.3 also produces a decrease in the overall number of M72-positive OSNs (Biju et al., 2008). To determine whether this occurred with chronic intranasal IND treatment, the same whole mounts described above were cryoprotected and coronally sectioned on a cryostat. Because the M72 glomeruli exist so close to the surface of the olfactory bulb, whole-mount X-gal staining time can be significantly reduced, thus eliminating nonspecific background staining of the olfactory epithelium. After fully exposing the olfactory bulb, if the outer membrane just underneath the bone covering the snout is left intact, little X-gal staining is observed in the epithelium. After $6 \mathrm{~h}$ of treatment in buffer $\mathrm{C}$, there is some nonspecific background staining in the epithelium; however, when whole mounts are sectioned at $25 \mu \mathrm{m}$, nonspecific back-

ground color cannot be observed. Thus, whole-mount images as well as coronal sections from the same animal can favorably be obtained (Fig. $4 A^{1}-D^{1}$ ). Sections were counterstained with neutral red to count the number of M72-positive OSNs for each animal sampled across $\sim 2600 \mu \mathrm{m}$ of the epithelium (Fig. $4 A^{2}-$ $D^{2}$ ). There was no significant difference observed in the numbers of LacZ-positive neurons counted between any treatment groups (insulin, $2427 \pm 266$; vehicle, $2672 \pm 604$; boiled, $2824 \pm 299$; untreated, $2932 \pm 263$ ). Additionally, the mean width of the longest axis and the cross-sectional area of M72-positive glomeruli was obtained and compared between IND treatment groups

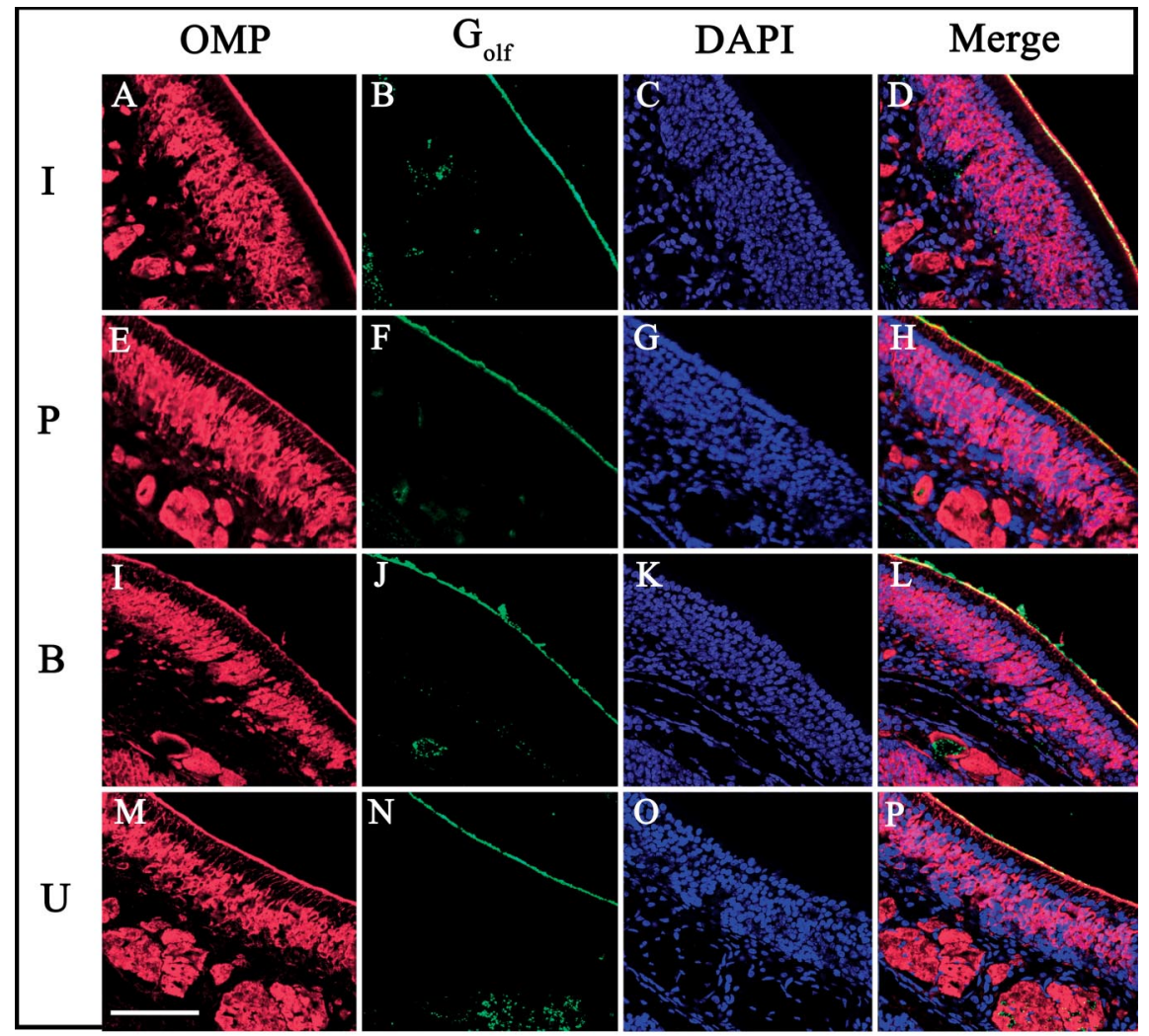

$\mathrm{R}$

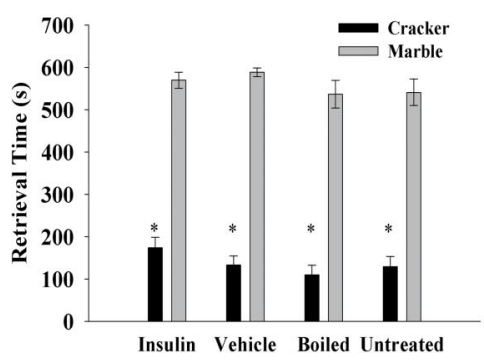

Figure 3. IND treatment does not damage the olfactory epithelium, decrease olfactory sensory neuron numbers, or cause general anosmia. $\boldsymbol{A}-\boldsymbol{P}$, Representative coronal sections $(16-20 \mu \mathrm{m})$ of the MOE were double immunolabeled with $\alpha 0 \mathrm{MP}(\boldsymbol{A}, \boldsymbol{E}$, $\boldsymbol{I}, \boldsymbol{M})$ and $\alpha \mathrm{G}_{\text {olf }}(\boldsymbol{B}, \boldsymbol{F}, \boldsymbol{J}, \boldsymbol{N})$, and then stained with the nuclear marker $\operatorname{DAPI}(\boldsymbol{C}, \boldsymbol{G}, \boldsymbol{K}, \mathbf{0})$. Sections were acquired from awake mice receiving IND treatment (I, insulin; P, PBS control; B, boiled insulin) or handled but not treated (U, untreated) for $7 \mathrm{~d}$. ImmunolaNote: OMP-positive OSN cell bodies and axon bundles are clearly visible, as well as $G_{\text {olf }}$ immunoreactivity in the cilia layer. Scale bar, $50 \mu \mathrm{m}$. Q, Bar graph plot of the mean number ( \pm SEM) of OMP/DAPI positive cells per $300 \mu \mathrm{m}$ of epithelium on two ectoturbi$\alpha 0 \mathrm{MP}$ and stained with DAPI, and digital images from each channel were captured and merged. The means were not significantly of a hidden food odor (cracker) or similarly shaped object (marble) as a test for general anosmia for five awake IND-treated mice as indicated. *Significantly different by Student's $t$ test, $\alpha=0.05$.

(Fig. $4 E, F)$. There was no statistical difference between long-axis width or glomerular cross-sectional area between any IND treatment groups. Thus, chronic insulin IND treatment does not affect glomerular position, size, axonal projection, nor the numbers of M72-positive OSNs.

\section{Chronic intranasal insulin treatment does not alter} peripheral glucose homeostasis

Central delivery of insulin is not reported to alter peripheral blood glucose (Reger and Craft, 2006; Benedict et al., 2008; Hallschmid et al., 2008); therefore, it was not anticipated that the 

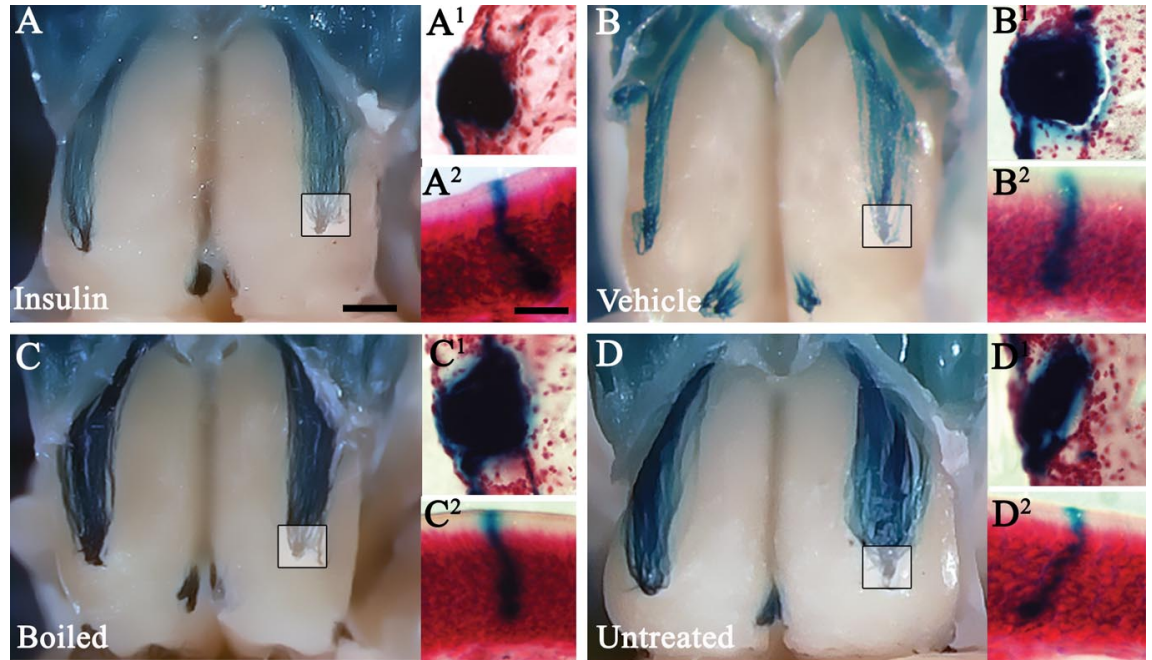

$\mathrm{E}$

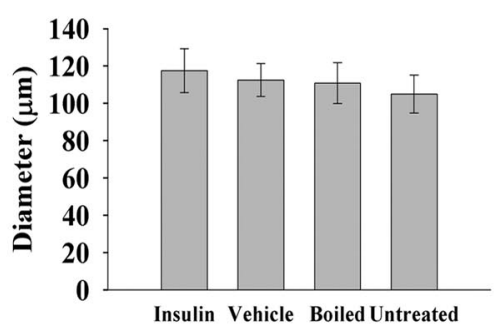

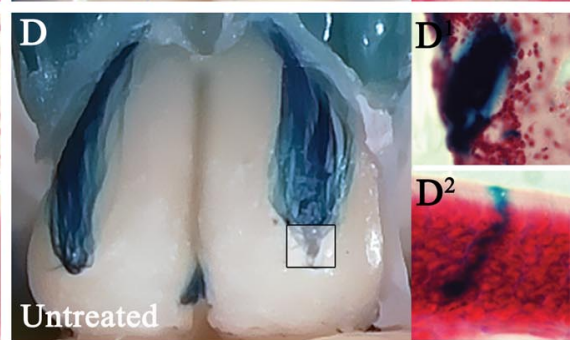

F

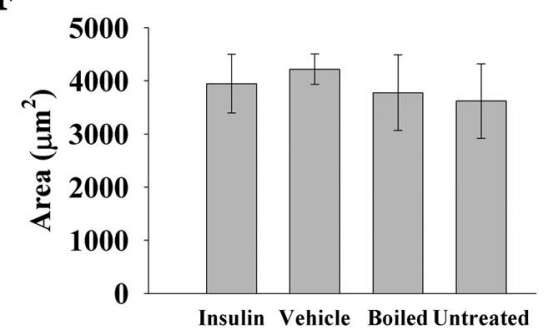

Figure 4. Insulin IND treatment does not affect glomerular position, diameter, or cross-sectional area. $A-D$, Representative whole-mount images of awake M72TauLacZ mice IND treated as in Figure 3. The inset box represents area of tracked M72 glomerulus after coronal sectioning and counterstaining staining with neutral red as shown in single prime lettering, respectively $\left(\boldsymbol{A}^{\mathbf{1}}, \boldsymbol{B}^{\mathbf{1}}, \boldsymbol{C}^{\mathbf{1}}, \boldsymbol{D}^{\mathbf{1}}\right)$. Double prime lettering $\left(\boldsymbol{A}^{\mathbf{2}}, \boldsymbol{B}^{\mathbf{2}}, \boldsymbol{C}^{\mathbf{2}}, \boldsymbol{D}^{\mathbf{2}}\right)$ are representative M72-positive OSNs sampled in the epithelium from animals in the respective treatment groups. Mice ( $N=4$ per treatment group) were IND-treated for $7 \mathrm{~d}$. Note: No gross change in OSN morphology or axonal targeting to the M72 specific glomerulus was apparent. Histogram summary of the mean ( \pm SEM) glomerular diameter $(\boldsymbol{E})$ or cross-sectional area $(\boldsymbol{F})$ of the identified M72 glomerulus as in $\boldsymbol{A}^{\mathbf{1}}, \boldsymbol{B}^{\mathbf{1}}, \boldsymbol{C}^{\mathbf{1}}$, and $\boldsymbol{D}^{\mathbf{1}}$. Not significantly different, one-way ANOVA with a Student-Newman-Keuls post hoc test $(\alpha=0.05)$. Scale bar: $\boldsymbol{A}-\boldsymbol{D}, 1 \mathrm{~mm} ; \boldsymbol{A}^{\mathbf{1}}-\boldsymbol{D}^{\mathbf{1}}, 50 \mu \mathrm{m}$; $A^{2}-D^{2}, 10 \mu \mathrm{m}$.

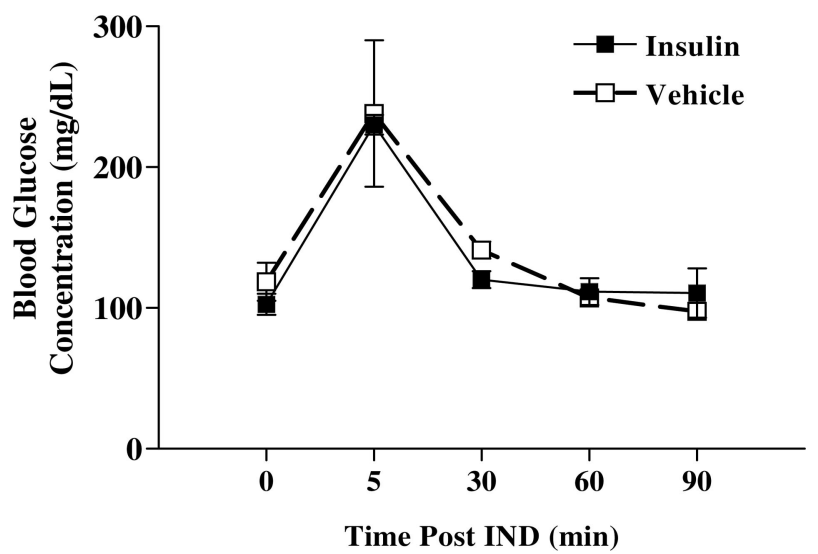

Figure 5. Insulin IND treatment does not alter peripheral glucose. Line graph of the mean ( \pm SEM) resting (fed) blood glucose when acutely measured after awake insulin ( $\square$ ) or vehicle control $(\square)$ IND, as repeatedly sampled from the tail. Final measurements were sampled by trunk bleeds (see Results). NS, Not significantly different mean ( \pm SEM) by Student's $t$ test, $\alpha=0.05$; insulin $(N=5)$ or vehicle control $(N=4)$ IND.

IND-treated mice would undergo repetitive hypoglycemia that would impact behavior or associated metabolism. To confirm that this was indeed so under our experimental paradigm, blood glucose was measured in awake insulin IND-treated mice at time intervals subsequent to IND as reported in Figure 5. Although the mean, nonfasting glucose level was near $100 \mathrm{mg} / \mathrm{dl}$ before IND treatment by tail sampling (PBS vehicle, 118.5; insulin, 102.5; not significantly different, Student's $t$ test, $\alpha=0.05$ ), glucose levels rose sharply and quickly fell at the 5 min time point in all animals, presumably in concert with the stress of handling. After $7 \mathrm{~d}$ IND treatment, blood glucose level as sampled by trunk bleed (in milligrams per deciliter) was not significantly different between insulin- or vehicle-treated animals (PBS vehicle, $88.3 \pm 3.4, n=4$; insulin, $88.4 \pm 2.8, n=$ 5; Student's $t$ test, $\alpha=0.05$ ), and neither treatment group had a blood glucose level that fell outside of that considered normal. Consistent with measured glucose homeostasis, ELISA analysis of serum plasma harvested from an identical collection period also revealed no change in peripheral hormone levels after $7 \mathrm{~d}$ of insulin or vehicle IND treatment (data not shown).

\section{Chronic intranasal insulin treatment enhances short- and long-term object memory recognition}

Intranasal insulin is known to affect working memory and spatial learning (Craft et al., 1999; Park et al., 2000; Benedict et al., 2004) (for review, see Plum et al., 2005), so it was of interest to test object memory recognition in IND-treated mice. Additionally, memory is required for the twochoice paradigm for odorant threshold, so it was also necessary to ascertain adequate memory function to proceed with that paradigm. Both short- and long-term object memory tests were performed on insulin, PBS, boiled insulin, and untreated mice (Fig. 6). The tests were performed as described in Materials and Methods, and the percentage exploratory time for each object was scored. When mice were exposed to the initial two unfamiliar objects (objects 1 and 2), they spent $\sim 50 \%$ of their time exploring each, indicating there was no bias across the objects or position during the familiarization phase. When then exposed to object 1 (now familiar) versus a novel object (object 3), their time of exploration of the novel object significantly increased as determined by a Student's $t$ test ( $\alpha \leq 0.05$ ). When exploratory times for the novel object are compared in both short-term $(1 \mathrm{~h})$ and long-term $(24 \mathrm{~h})$ memory recognition tests, mice in the insulin IND treatment group show a significantly longer time of exploration (85\%) than that of the other three groups $(65 \%)$. Thus, mice receiving insulin IND treatment exhibit short- and long-term object memory retention that is consistent with reports of clinical trials (for review, see Strachan, 2005; Hallschmid et al., 2008) and would not be predicted to perform poorly in olfactory threshold testing that requires memory.

\section{Chronic insulin IND treatment evokes anxiolytic effects}

During initial insulin IND treatment trials, it was observed that insulin-treated mice displayed far less resistance to hand restraint 
and insulin delivery. To systematically explore this unusual behavior, a well described LDB paradigm for testing levels of anxiety was used as first described by Blumstein and Crawley (1983) (see Materials and Methods) (Fig. 7). Mice were tested $1 \mathrm{~d}$ before IND treatment began (day 0$)$, received IND treatment for $6 \mathrm{~d}$, and were retested at the end of day 6 . Several laboratories have documented that repeated trials separated by an interlude of several days does not affect behavior performance (Barry et al., 1987; Onaivi and Martin, 1989). Time in light, transitions, and latency on day 6 were normalized to that of day 0 and compared using a paired $t$ test $(\alpha=0.05)$ within treatment. Insulin IND-treated mice spent a significantly longer amount of time in the light chamber, whereas there was no difference among groups in the number of transitions between chambers (Fig. $7 A, B$ ). Insulin IND-treated mice showed no change in latency; however, PBS and boiled insulin mice showed a significant decrease in latency on day 6 (data not shown). Untreated mice showed no decrease in latency; hence it appears that repeated handling over 6 d evokes a significant decrease in latency of entrance into the dark chamber. Insulin IND treatment, therefore, appears to reverse this handling-induced decrease in latency.

The light/dark box is an excellent test to determine levels of anxiety and drugs or compounds that increase time in light are referred to as anxiolytic (Imaizumi et al., 1994a,b,c). It is also prudent, however, to test parallel anxiety paradigms to strongly confirm phenotype. We therefore decided to extend the LDB anxiety testing by performing two subsequent tests that are indicators of anxiety behavior: MB behavior and EPM performance. In parallel to the LDB-measured reduction in anxiety after insulin IND, mice receiving vehicle control IND buried significantly more marbles after treatment, whereas those animals receiving insulin solutions did not (Fig. 7C) (paired $t$ test, $\alpha=0.05$ ). Since these tests were designed as a paired metric, recording numbers of marbles buried within an animal before and after IND, the data indicate handling alone increases burying activity, but that application of insulin decreases this behavior. Performance in the EPM also identified changed anxiety state of the animals after insulin IND treatment for a proportion of the measured parameters. Animals that received vehicle control IND spent significantly less time in the open arms of the maze after $7 \mathrm{~d}$ of treatment, whereas animals receiving insulin were not significantly different from during pretreatment performance (Fig. 7D) (paired $t$ test, one-tailed, $\alpha=0.05$ ). The identical result was achieved when scoring number of entries into the maze open arms (Fig. 7E). Similar to what was observed in the LDB paradigm, IND treatment did not differentially affect total arm entries or number of transitions; however, both sets of animals showed a reduction in transitions over time, presumably indicative of handling alone (Fig. $7 F)$. Collectively, the results of the three anxiety tests demonstrated that chronic insulin IND treatment evokes anxiolytic behavior and does not affect basic locomotor activity.

\section{Chronic insulin IND treatment affects odor habituation for two sets of odorants}

Gene-targeted deletion of Kv1.3 produces an increased discrimination between two odor molecules as assessed via odor habitu-
B

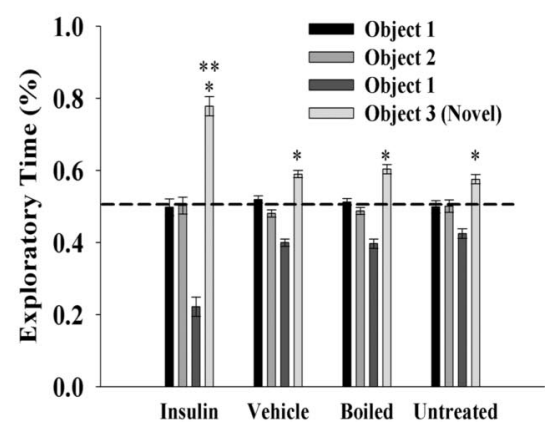

ation paradigms (Fadool et al., 2004). It was hypothesized that chronic insulin IND treatment, which would be predicted to elicit strong phosphorylation of Kv1.3 and correlate current suppression, might mimic such effects as observed in the Kv1.3-null mice. Mice received IND treatment of insulin, PBS, or boiled insulin for $5 \mathrm{~d}$, and on the sixth and seventh days, mice were subjected to an odor habituation trial that tested discrimination between two complex odorants, geranyl acetate and peppermint (Fig. 8A). There was also an age-matched group of animals that were not repeatedly treated or handled (untreated). All groups similarly habituated to the first odor of the pair (trials 1-7); however, insulin IND-treated mice showed a significant increase in mean exploratory time toward the unhabituated odorant (trial 8) (paired $t$ test, $\alpha=0.05$ ). We next tested the mice for discrimination between a more difficult odor pair consisting of two alcohols that differed by a single carbon atom (C9/C10) (Fig. 8 B). As with the complex odorant pair, insulin IND-treated mice significantly increased mean exploratory time for the unhabituated odor; however, the range in magnitude was less, implicating a greater difficulty in discrimination (geranyl acetate/peppermint odor pair, 3.3-4.8 $\times$ increase, vs C9/C10 odor pair, $2.1-2.7 \times$ increase) (Fig. $8 C$ ).

\section{Odorant threshold is not significantly affected by chronic insulin IND treatment}

Kv1.3-null mice exhibit an increased olfactory ability ("supersmeller") in terms of odor detection threshold (Fadool et al., 2004) that we conjectured might be mimicked via insulininduced Kv1.3 suppression. To address this question, a twochoice paradigm that defines odorant threshold based on decision to dig for an odor-paired food reward was performed as described in Materials and Methods. Because of the fact that there was no difference between IND treatment and control groups (PBS, boiled insulin, and untreated) for either behavior or biochemical experiments thus far examined, combined with the length and complexity of training for the two-choice paradigm, only IND treatments testing the intact $(\mathrm{I}+)$ and the denatured hormone (B) were examined. Mice were initiated into the threshold testing phase of the paradigm for a period of $3 \mathrm{~d}$ while carefully decreasing their body weight to $75-85 \%$ of ad libitum feeding body weight (testing days 4-6) (Fig. 9A). Both groups of mice demonstrated $94-100 \%$ correct decisions for peppermint odor dilutions ranging from $10^{-1}$ to $10^{-7}$. For the $10^{-8}$ dilution, both 
A

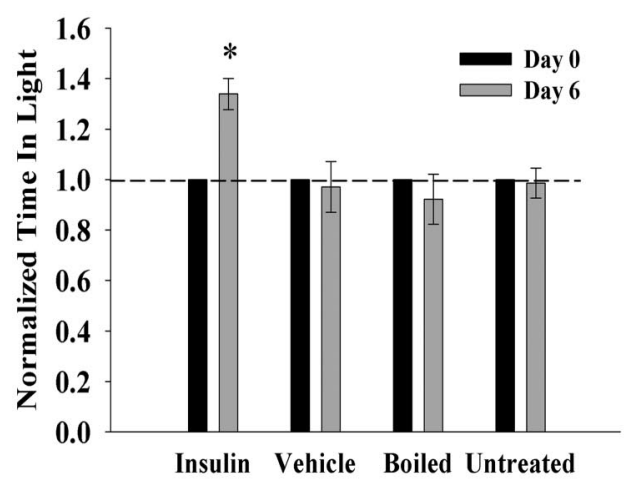

D

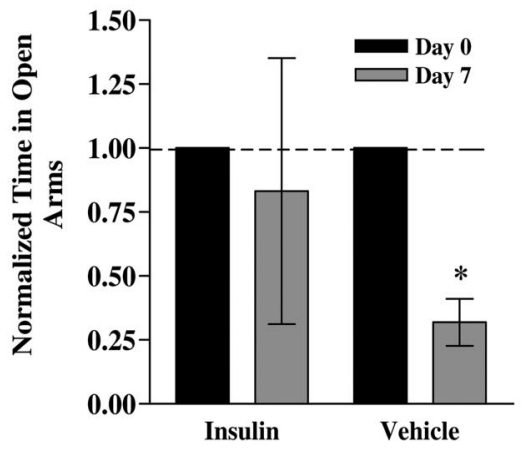

B

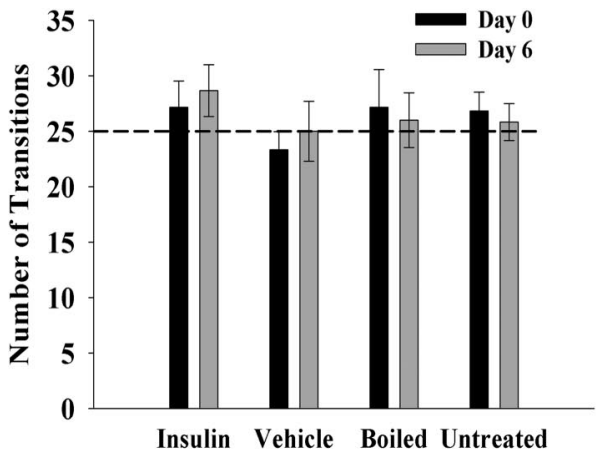

$\mathrm{E}$

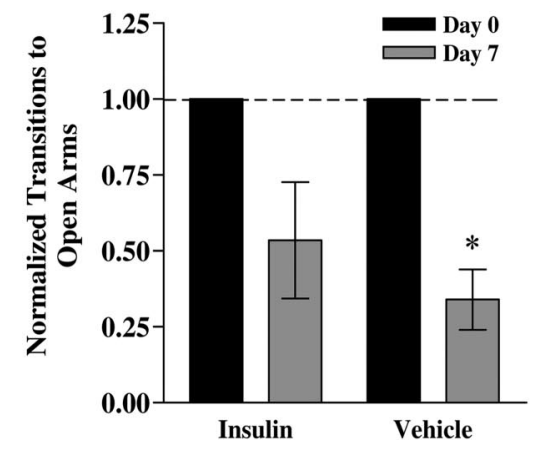

$\mathrm{C}$

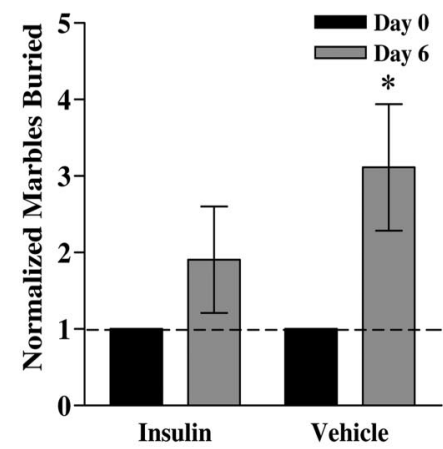

$\mathrm{F}$

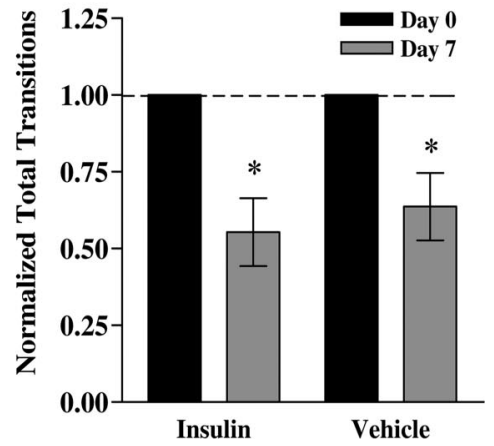

Figure 7. Insulin IND treatment evokes anxiolytic affect in three paradigms to measure anxiety behavior. Bar graph summary of the time spent in the light ( $\boldsymbol{A}$ ) and the number of transitions across compartments $(\boldsymbol{B})$ for mice receiving awake IND treatment and then challenged with the LDB behavioral task. Mice ( $N=5$ per treatment group) were subjected to a light/dark box paradigm (for details, see Materials and Methods) $1 \mathrm{~d}$ before IND treatment (day 0 ) and after $6 \mathrm{~d}$ of IND treatment (day 6 ). Age-matched untreated animals were included and tested in the same manner (untreated), but not given any IND treatment in the intervening days between tests. $\boldsymbol{A}$, Dashed line, Ratio of light/dark of 1.0. B, Dashed line, Mean reported values for (57B6/J mice using this standard paradigm. C, Bar graph summary of the portion of marbles buried in a 45 min trial interval for mice receiving insulin (insulin) or control vehicle (vehicle) via IND. Marble-burying behavior was assessed $1 \mathrm{~d}$ before IND treatment (day 0 ) and after $6 \mathrm{~d}$ of awake IND treatment (day 6 ) for five and four mice, respectively, in each group. $\boldsymbol{D}-\boldsymbol{F}$, Bar graph summaries of the mean time spent in open arms $(\boldsymbol{D})$, number of transitions to open arms $(\boldsymbol{E})$, and total number of transitions $(\boldsymbol{F})$ for mice receiving insulin (insulin) or control vehicle (vehicle) and then challenged with the EPM behavior task. EPM behavior was assessed $1 \mathrm{~d}$ before IND treatment (day 0 ) and after $7 \mathrm{~d}$ of awake IND treatment (day 7 ) for five mice in each treatment group. * Significantly different mean ( \pm SEM) after repeated measure (within treatment) by paired $t$ test, $\alpha=0.05 . \boldsymbol{B}, \boldsymbol{F}$, Note number of transitions across IND treatment is not different across treatments, indicating that basal locomotor activity in these paradigms is not affected by IND treatment.

groups of mice performed at $\sim 80 \%$ correct decisions. At this point, behavioral testing was stopped, and IND treatment was started for a period of $5 \mathrm{~d}$ (testing days 7-11). After $5 \mathrm{~d}$ of IND treatment, behavioral testing was resumed at the $10^{-8}$ peppermint dilution. Neither group of mice showed a significant increase in decision performance in the second $10^{-8}$ peppermint dilution trial. Boiled insulin IND-treated mice reached their odorant threshold at $10^{-10}$, at which percentage correct decision was $55 \pm 10 \%$. Insulin IND-treated mice performed better at $10^{-10}$ and were able to continue one order of magnitude lower to the $10^{-11}$ peppermint dilution (Fig. 9B). Thus, insulin INDtreated mice appear to have a decreased odor threshold that is only slightly better than that of boiled insulin IND-treated animals. There was a trend that insulin IND-treated mice took less time to make a decision (Fig. 9C) and made less transitions across compartments before digging (decision) (Fig. 9D); however, these values did not reach statistical significance (Student's $t$ test, $\alpha=0.05$ ).

\section{Insulin IND treatment slightly reduces body weight}

Intranasal insulin evokes a reduction in body weight that appears to be sex-selective based on the given dosage (Schwartz 2000; Hallschmid et al., 2004). To determine whether $5 \mu \mathrm{g} / \mu \mathrm{l}$ insulin
IND treatment evoked a similar body weight decrease, mouse weights were recorded before the first IND treatment, and before the killing. Data analysis using a paired $t$ test ( $\alpha=0.05)$ demonstrated that there was no significant difference between day 1 and day 7 weights in any IND treatment group (data not shown). There was, however, a slight noticeable body weight reduction trend in insulin IND-treated animals of $5 \pm 0.01 \%$. Although this change is not statistically significant, it remains unclear whether longer insulin IND treatment might evoke a stronger decrease body weight over the treatment course.

\section{Insulin and IR expression in the olfactory epithelium}

The distribution for insulin and insulin receptor kinase have been well characterized in the OB (Young et al., 1980; Baskin et al., 1983; Hill et al., 1986; Matsumoto and Rhoads, 1990; Wickelgren, 1998; Fadool et al., 2000; Marks and Fadool, 2007), but their expression patterns in the epithelium, which could inherently contribute to olfactory behavior and detection, has only been recently reported (Lacroix et al., 2008). Moreover, Kv1.3 channel is not expressed in the epithelium (Biju et al., 2008); therefore, insulin-activated pathways specific to the epithelium would not involve channel modulation. To determine the extent of peripheral insulin distribution in the MOE after chronic IND treatment, 
A

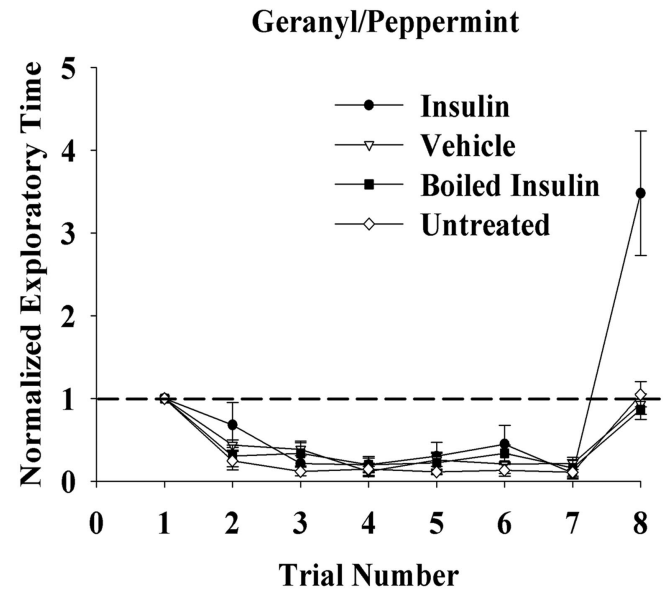

B

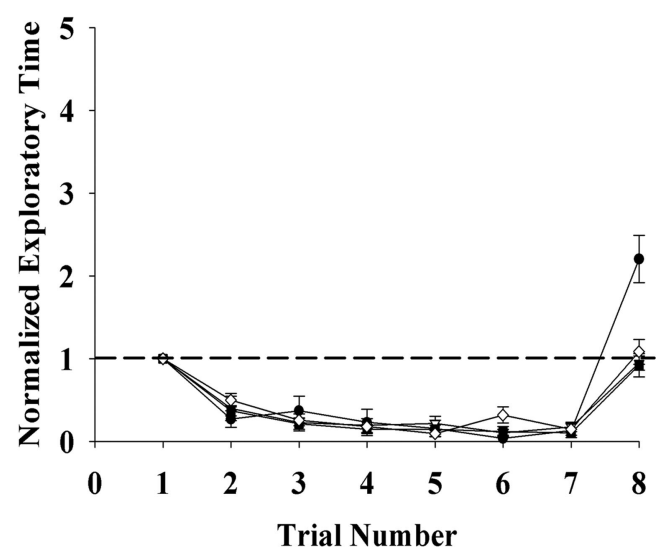

C

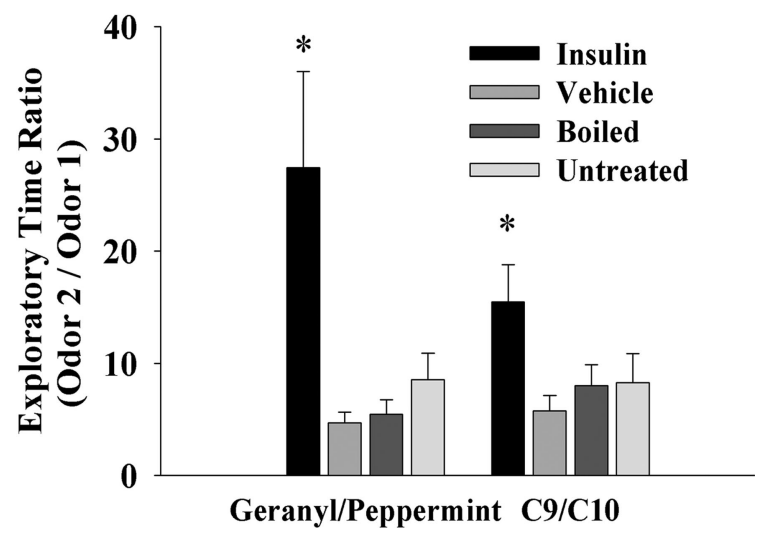

Figure 8. Insulin IND treatment increases odor discrimination in an odorant habituation paradigm. $\boldsymbol{A}, \boldsymbol{B}$, Line graph of the mean exploratory time of an odorant for awake IND-treated mice. Habituation is induced via repeated presentation of the first odorant of the pair at a frequency of $1 \mathrm{~min}$ (trials 1-7), followed by a test for discrimination after habituation via exposure to a second odor on trial 8 . Mice $(N=5$ per treatment group) were either challenged with an odor discrimination between mixtures (geranyl/peppermint) $(\boldsymbol{A})$ or a more difficult discrimination between a single odorant varying in chain length ( $(9 / C 10$ alcohol) $(\boldsymbol{B})$. Data are normalized (within animal) to the initial exploratory time on trial 1 to control for interanimal variability in oriented behavior. Dashed line, Ratio of 1.0. C, Bar graph of the mean exploratory time ratio (unhabituated/habituated) calculated by dividing the exploratory time of the novel odorant (trial 8) by that of the last exploratory time of the habituated odor (trial 7). Error bars indicate SEM. *Significantly different over trial, one-way ANOVA with Student-NewmanKeuls post hoc test, $\alpha=0.05$. turbinate sections from treated groups were labeled with $\alpha \mathrm{OMP}$, $\alpha$ Insulin, and DAPI. The insulin and boiled insulin IND treatment groups show strong immunoreactivity for insulin in all layers of the olfactory epithelium compared with basal insulin levels of vehicle IND-treated mice (Fig. $10 \mathrm{~B}, F, J$ ). Although boiling insulin breaks the intramolecular disulfide bonds and eliminates biological activity, the epitope to which the insulin antisera was raised apparently remains fully intact (Fig. $10 J$ ). The PBS treatment group demonstrated no insulin reactivity, whereas there appears to be very slight reactivity in the OSN cilia of the untreated group (Fig. 10F,N). To better resolve this and determine whether insulin exists natively in the untreated olfactory epithelium, more sensitive peroxidase-based immunostaining was performed on sections from untreated animals (Fig. 10Q,R). Very light insulin expression in the cilia can be observed (Fig. $10 R$ ) over that of the no primary condition (Fig. 10Q), indicating low levels of endogenous insulin within the epithelium.

Since the endogenous ligand was localized to the cilia, it was predicted that we should be able to detect the receptor here as well, and after IND treatment it might show an increase in phosphorylation. IR immunoreactivity in the olfactory cilia could be observed in untreated mice (Fig. $11 A-H$ ), which was confirmed by peroxidase-based staining to rule out nonspecific binding and edge effect (Fig. $11 I-K$ ). Moreover, lower magnification images of turbinates on adjacent sections stained by immunofluorescence and peroxidase-based methods demonstrate nearly identical labeling (Fig. $11 K, L$ ). It was hypothesized that, because much of IR expression was observed in the cilia, there would be a relatively small amount of IR protein expressed overall. Unlike previous quantifications of IR in $\mathrm{OB}$ membrane protein preparations (Fadool et al., 2000), IR protein could not be detected in the olfactory epithelium across a series of postnatal ages but could be concentrated sufficiently for immunoprecipitation (Fig. $11 \mathrm{M}$ ). If loaded protein is sufficiently increased over that which we typically separate for native SDS-PAGE analyses $(35 \mu \mathrm{g})$, then IR protein $\left(M_{\mathrm{r}}=97 \mathrm{kDa}\right)$ starts to be resolved between 60 and $80 \mu \mathrm{g}$ of loaded sample when coupled with high concentration of secondary antibody HRP conjugate (Fig. 11 N). Finally, insulin IND treatment does not robustly elevate $\alpha 4 \mathrm{G} 10$ labeling of phosphorylated proteins at the cilia of the epithelium (Fig. $12 B, F, J, N$ ), suggesting that the contribution of MOE-derived insulin pathways to behavior modulation may be minimal.

\section{Effect of diet-induced obesity (hyperglycemic state) on insulin IND-induced behaviors}

The hyperglycemic state of prediabetes is brought to homeostasis via a combination of diet, exercise, or pharmacologic intervention (Unger and Moriarty, 2008). We were therefore curious as to the memory- and anxiety-associated behaviors after elevation of brain insulin in an altered glycemic state. Animals were placed on a MHF diet and their weight was monitored weekly for 55 weeks (Fig. 13A). Mice on the MHF diet weighed significantly more than that of control fed mice after a period of 3 months as shown in the bar graph in Figure 13B. Unfasted blood glucose levels (in milligrams per deciliter)— determined by tail bleed before killing - were not measured until week 50 and demonstrate a significant increase that is consistent with chronic hyperglycemia or prediabetic blood chemistry (control fed, $104.5 \pm 7.8, n=4$; MHF diet, $139.6 \pm 6.5, n=5$; Student's $t$ test, $\alpha=0.05$ ). Because peripheral insulin levels (in nanograms per milliliter)—determined by ELISA from trunk blood isolated serum-were also now elevated (control fed, $4.5 \pm 0.1$, vs MHF diet, $13.1 \pm 0.13$ ) and presumably would have access across the blood-brain bar- 
A

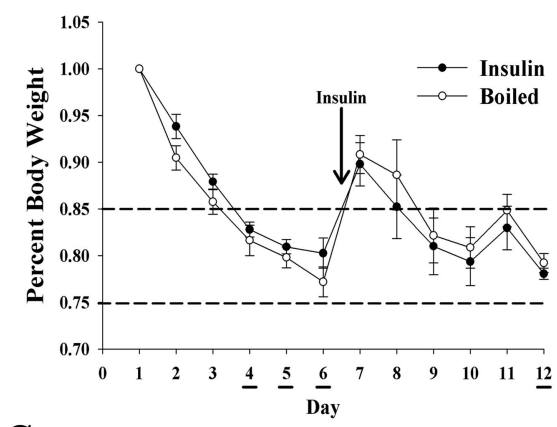

C

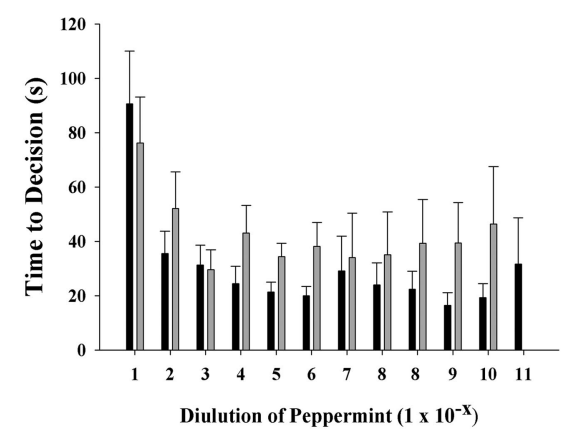

B

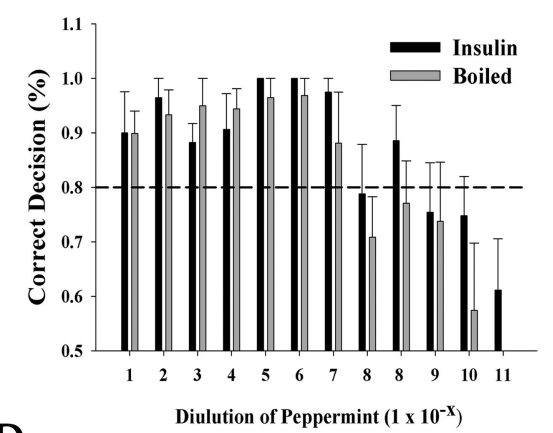

D

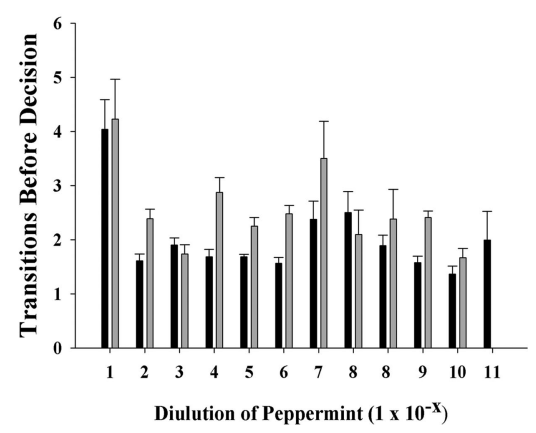

Figure 9. Insulin IND treatment only slightly affects odorant threshold and does not affect time to decision or the number of choices in a two-choice paradigm for odorant threshold. $\boldsymbol{A}$, Line graph of the mean body weight for awake IND-treated mice in which either insulin $(O)$ or boiled insulin $(\bigcirc)$ was administered on days 7-12. Body weights were carefully lowered via food restriction to $75-85 \%$ ad libitum feeding body weight during important days of the two-choice paradigm in which mice were scored for correct decision (dig) to receive a hidden food reward (honey-flavored cereal) buried under peppermint-scented litter. Working trial days are denoted by underlining and start of the IND treatment is indicated by the arrow. $\boldsymbol{B}-\boldsymbol{D}$, Histogram plot of the percentage correct decision $(\boldsymbol{B})$, the time to reach decision $(\boldsymbol{C})$, and the number of transitions before decision versus odorant concentration $(\boldsymbol{D})$ represents the mean $( \pm S E M)$ for 8 mice in each of the two treatment groups (insulin, solid bar; boiled insulin, open bar). Each property on the abscissa was plotted against successive 10 -fold diluted odorant concentration as indicated on the ordinate $\left(1 \times 10^{-x}\right)$. Acquisition of behavior task took place on testing days $4-6$, during which mice first fell at or below $80 \%$ correct decision ( $\boldsymbol{B}$, dashed line). After $5 \mathrm{~d}$ of IND treatment (days 7-11), mice were retested at the $1 \times 10^{-8}$ odorant concentration (day 12) through a series of dilutions until odorant detection threshold was reached ( $50 \%$ correct choice, equivalent to chance alone). Note: Insulin IND-treated mice were able to detect odorant at 1 log unit lower magnitude than that of boiled insulin-treated mice $(\boldsymbol{B})$, but neither treatment yielded a significant difference in the time to make a decision $(\boldsymbol{C})$ nor number of transitions between choices $(\boldsymbol{D})$.

rier, we wanted to compare Kv1.3 basal phosphorylation versus that after insulin IND to determine whether there was insulin resistance. Most interestingly, the increase in insulin-induced Kv1.3 phosphorylation via IND was significantly less in the OBs from mice raised on the MHF diet compared with that from mice maintained on control diets (Fig. 13C) (Student's $t$ test, $\alpha=$ 0.05 ). Given changes in blood chemistry and altered phosphorylation of known IR kinase substrates, we explored any dampening effects of insulin IND on object memory or anxiety-associated behaviors. Because of the number of behavioral phenotyping tasks and the importance of minimizing handling to $\sim 15$ min per day (see Materials and Methods), diet-induced obese mice were only tested for long-term $(24 \mathrm{~h})$ and not also short-term $(1 \mathrm{~h})$ object memory (Fig. 14A). Most interestingly, unlike that of control fed, insulin IND-treated animals (Fig. 6B), mice that became obese and hyperglycemic via a MHF dietary regimen, no longer exhibited an increased object memory performance when administered insulin IND even though control vehicle IND-treated obese animals still retained a preference for the novel object, signifying adequate performance for long-term object memory (Fig. 14A). When comparing across the three paradigms used to phenotype anxiety-related behaviors in control fed mice (Fig. 7), application of these same paradigms in the obese mice yielded differential effects depending on task. In both the LDB and the EPM paradigms, the number of transitions (either across light/dark compartments or across open/closed arms of the maze) was not significantly different across IND or diet treatment (data not shown), which inferred that the increase in weight gain of the obese animals did not affect movement ability for these tasks. In the LDB paradigm, the control fed insulin IND-treated animals did not exhibit a changed percentage of time spent in the light after $5 \mathrm{~d}$ of IND treatment (Fig. $14 B$, bar graph 1) (paired $t$ test, $\alpha=0.05$ ). Since the additional variable between the two groups of insulin IND-treated animals phenotyped in the LDB paradigm (compare Figs. $7 A, B, 14 B$ ) was age ( 6 weeks vs $>1$ year), we additionally tested control fed vehicle IND-treated animals that were aged matched. Unlike that of the younger animals, $>1$ year adult animals that were control fed and vehicle IND-treated exhibited a decreased percentage of time spent in the light after $5 \mathrm{~d}$ of IND treatment (Fig. $14 \mathrm{~B}$, bar graph 3). Under a MHF dietary regimen, insulin IND-treated mice no longer exhibited an equal percentage of time spent in the light before and after IND treatment (Fig. 7D) but, rather, exhibited a decreased percentage of time spent in the light (Fig. 14B, bar graph 2). These collective LDB data infer that the hyperglycemic condition of diet-induced obesity blocked the ability of insulin IND treatment to stabilize or reduce anxiety. The MB paradigm indicated that dietinduced obesity had no effect on marbleburying behavior in that the number of marbles buried by the insulin IND-treated animals was independent of whether they were control or MHF diet fed (Figure 14C) (paired $t$ test, $\alpha=0.05$ ). The EPM paradigm indicated that dietinduced obesity decreased the time animals spent in the open arms, indicating a state-dependent change in anxiety-related behaviors for this task. Both control and MHF diet fed animals that were administered insulin IND treatment showed a reduction in time spent in the open arms of the plus maze (Fig. 14D, bar graph 1,2 ), whereby the MHF diet fed animals reached statistical significance (paired $t$ test, $\alpha=0.05$ ). Similar to what was observed in the LDB paradigm, the vehicle IND-treated animals rarely entered the open arm at all compared with insulin IND-treated animals, indicating that their anxiety set point was significantly different from that of control fed animals after $9 \mathrm{~d}$ of insulin.

\section{Discussion}

We demonstrate that chronic IND treatment of awake mice is a reliable method to deliver a modulatory and metabolic hormone across the blood-brain barrier, evoking changes in olfactory bulb biochemistry and related behaviors. IND treatment does not cause damage to the olfactory epithelium nor does insulin IND treatment perturb OR-specific patterns of axonal targeting to 
defined glomeruli, size and abundance of glomeruli, or number of developing olfactory sensory neurons. After insulin IND treatment, however, measurable changes in ion channel phosphorylation are observed as well as alteration of protein-protein interactions with a major voltagedependent potassium channel in the olfactory bulb. At the behavioral level, animals demonstrate a trend in weight loss, and significant changes in object memory performance, levels of anxiety, and increased olfactory discrimination. Given that expression of insulin receptor kinase is among the highest in the $\mathrm{OB}$ of all brain regions (Hill et al., 1986; Schulingkamp et al., 2000), and the fact that this region of the brain is the first to receive insulin when clinically delivered via nasal sprays through passages in the cribriform plate (Kern et al., 1999; Dhanda et al., 2005), it is important to carefully examine the many potential olfactory targets for modulation that this hormone might evoke to elucidate the basis of potential side effects of therapeutic insulin IND treatment.

Our data support a changed level of Kv1.3 phosphorylation after a single session of insulin IND treatment consisting of 10 alternating naris deliveries to achieve a final estimated dose of $3.3 \mathrm{ng} / \mu \mathrm{l}$ insulin into the OB. The effect of chronic insulin IND treatment in the awake animal further enhanced the level of Kv1.3 phosphorylation to $\sim 2.5$-fold that of basal. Although it is not certain whether delivery was less efficient in the anesthetized state using a single session treatment or whether the accentuated increase in phosphorylation observed for the awake delivery was attributable to repeated treatment, a weeklong treatment is better representative of the biochemical changes likely induced after chronic use of insulin IND. The activation of IR kinase supported by the fourfold increase in autophosphorylation of the receptor would be anticipated to phos-

phorylate many downstream signaling cascades in OB neurons that are typically activated to achieve the well known pleiotropic effects of insulin signaling in other cells (Neubauer and Kulkarni, 2006; McNay, 2007). Kv1.3 channel is only one of those known downstream substrates; however, even when only considering ion channels as substrates, many voltage- and ligand-gated channels are known to be modulated by insulin signaling pathways (Van Buren et al., 2005; Gao et al., 2006; O’Malley and Harvey, 2007), thereby serving as potential targets for modulation in this and other brain regions reached by the nasally delivered insulin. The molecular/structural basis for coassociation of the synaptic protein PSD-95 and the Shaker family of voltage-gated potassium ion channels Kv1.x has been well explored (Kim et al., 1995; Arnold and Clapham, 1999; Marks and Fadool, 2007), but it is interesting that insulin enhances the adaptor protein interaction with the channel, indicated by increased coimmunoprecipita-

\section{OMP}
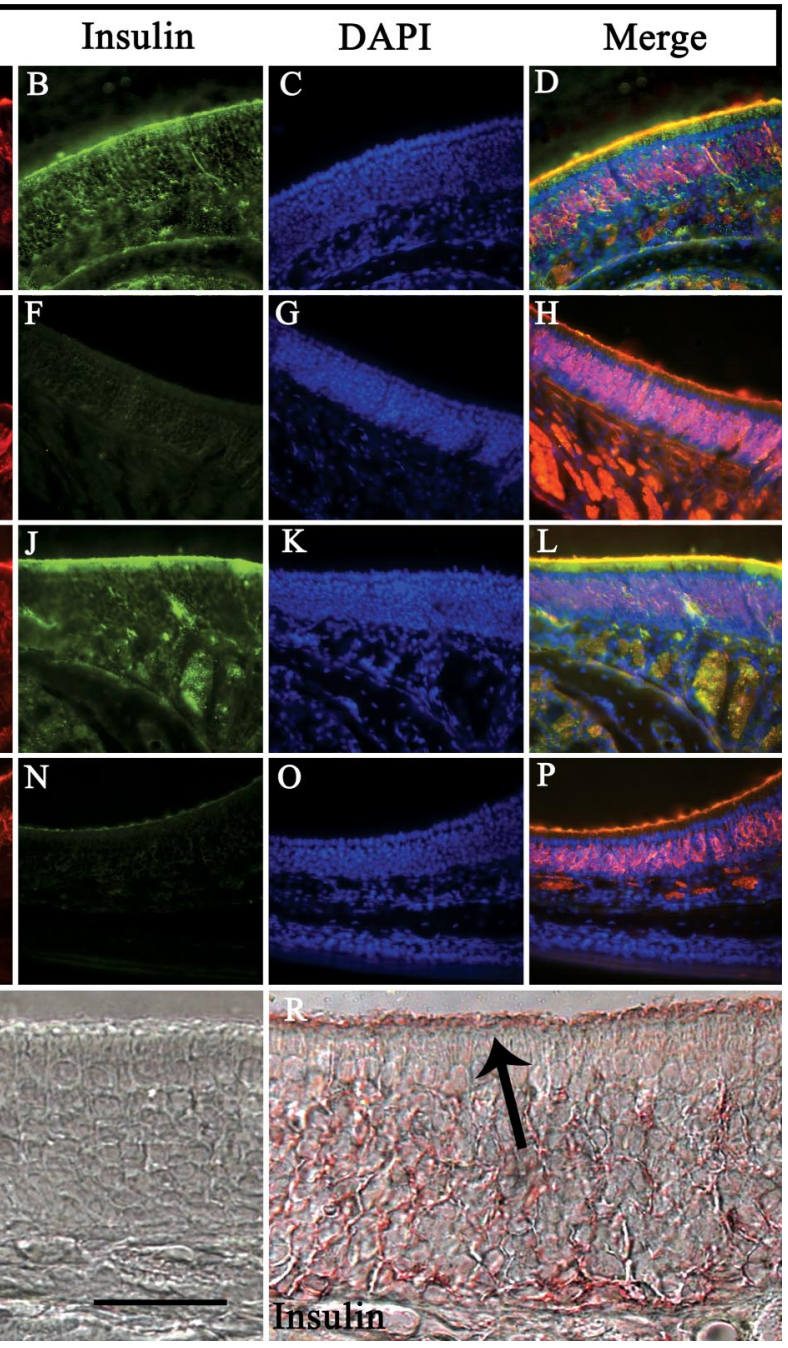

Figure 10. Insulin expression in the main olfactory epithelium after IND treatment. $\boldsymbol{A}-\boldsymbol{P}$, Representative coronal sections $(16-20 \mu \mathrm{m})$ of the MOE were double immunolabeled with $\alpha 0 \mathrm{MP}(\boldsymbol{A}, \boldsymbol{E}, \boldsymbol{I}, \boldsymbol{M})$ and $\alpha$ Insulin $(\boldsymbol{B}, \boldsymbol{F}, \boldsymbol{J}, \boldsymbol{N})$, and then stained with the

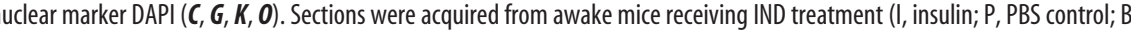

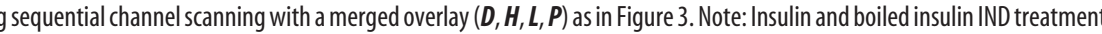
(B, $\boldsymbol{J})$ show robust insulin immunoreactivity in all epithelial layers, especially in the cilia layer. PBS vehicle IND and untreated animals $(\boldsymbol{N})$ display virtually no insulin immunoreactivity. Representative sections in which peroxidase-based immunolabeling was used for immunodetection of the primary antibody in untreated animals. $\boldsymbol{P}$, No primary (NP) control section. $\boldsymbol{R}$, Moderate insulin immunoreactivity in all layers of the epithelium, with labeling present in the cilia layer in which odor transduction machinery is expressed (arrow). Scale bars: $\boldsymbol{A}-\boldsymbol{P}, 100 \mu \mathrm{m} ; \mathbf{Q}, \boldsymbol{R}, 25 \mu \mathrm{m}$.

tion. Not only are previously reported protein-protein interactions with the channel enhanced, such as that with PSD-95 or IR (Marks and Fadool, 2007), but proteins that we previously demonstrated do not coimmunoprecipitate, such as IR and PSD-95, now have the capacity to complex after insulin stimulation.

A comparison of mice with Kv1.3 gene-targeted deletion (absence of channel protein) with that of mice with insulin IND treatment (reduction in Kv1.3 current via channel phosphorylation) provides important insights into the role of the ion channel in olfactory signaling. Insulin IND treatment does not evoke the anatomical phenotype of the gene-targeted deletion, namely increased number of glomeruli, decreased size of glomeruli and abundance of olfactory sensory neurons, supernumerary axonal projections of genetically tagged OR-expressing OSNs to defined glomeruli, and increased expression of olfactory transduction proteins such as $\mathrm{G}_{\text {olf }}$ (Fadool et al., 2004; Biju et al., 2008). A 

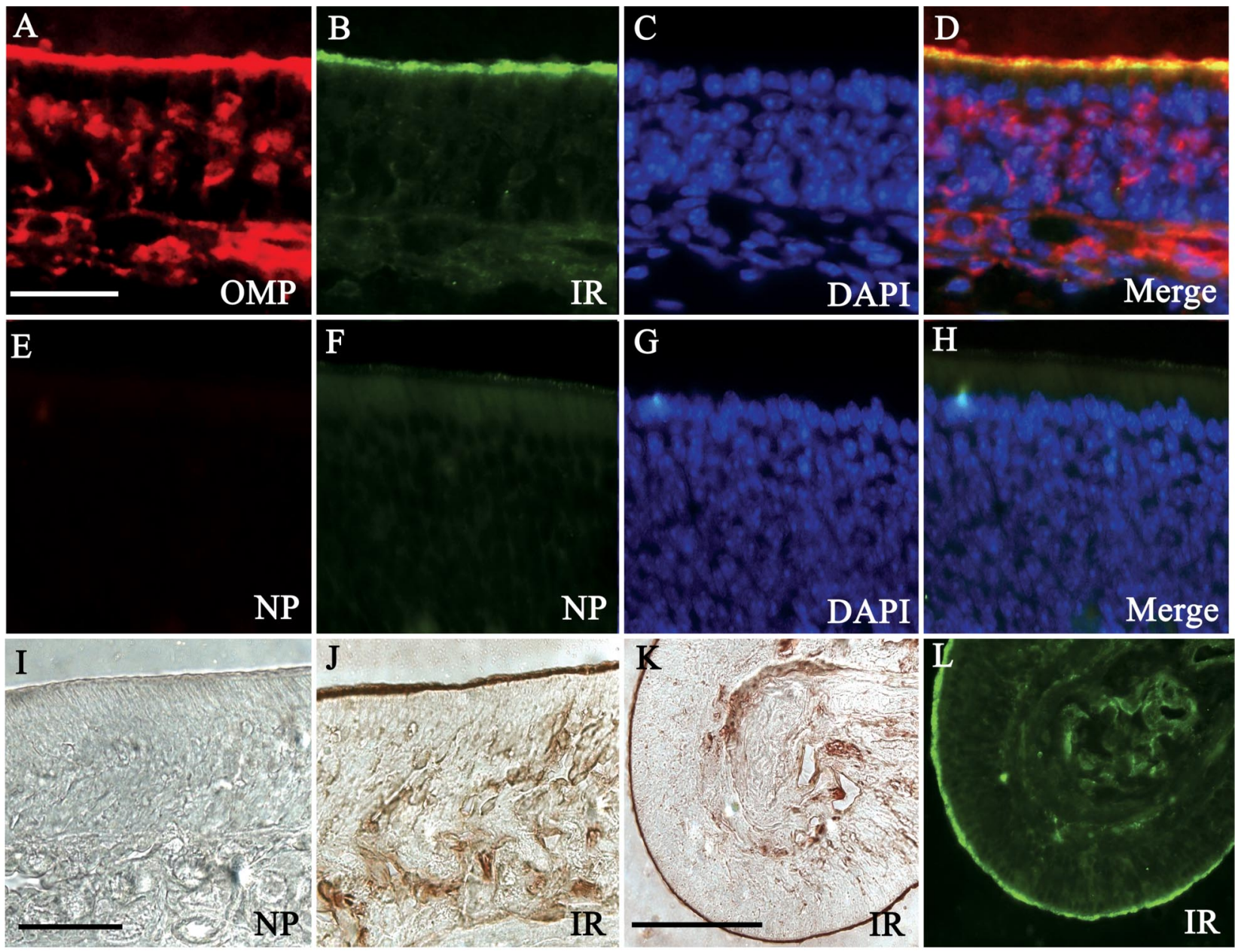

M

$\mathrm{N}$

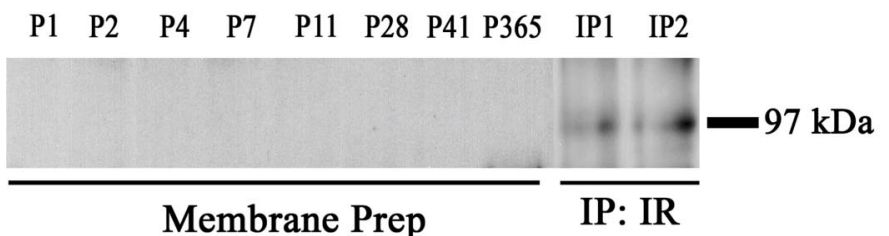

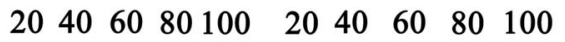

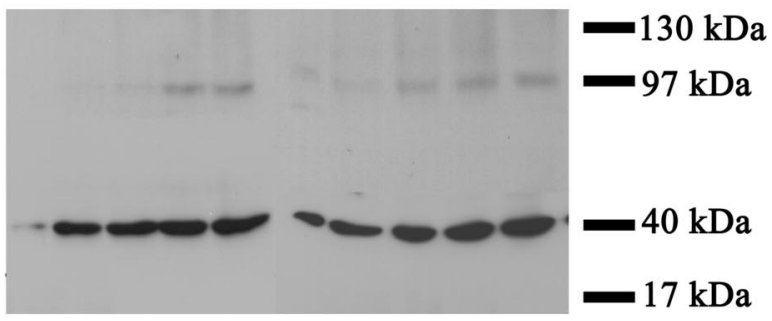

Blot: IR

Top: Blot IR

Top: Blot: IR

2Ab: 1:5000 DAR

2Ab: 1:4000 DAR

\section{Bottom: Blot $\alpha$ actin Bottom: Blot $\alpha$ actin}

Figure 11. IR expression in the olfactory epithelium. Same as in Figure 10, but for untreated mice double immunolabeled with $\alpha-0 \mathrm{MP}(\boldsymbol{A})$ and $\alpha-\operatorname{IR}(\boldsymbol{B})$, and then stained with DAPI $(\boldsymbol{C})$, and merged (D) to determine the distribution of IR in the epithelium. $\boldsymbol{E}-\boldsymbol{H}$, No primary controls (NP) demonstrating lack of immunoreactivity in the absence of $\alpha 0 \mathrm{MP}$ or $\alpha \mathrm{IR}$ primary antisera. $\boldsymbol{I}, \boldsymbol{J}$, Peroxidase-based immunolabeling: no primary control (NP) when IR antisera is omitted $(\boldsymbol{I}), \alpha \operatorname{IR}(J) . \boldsymbol{K}, \boldsymbol{L}$, Low field magnification of $\alpha \mid \mathrm{R}$ labeling using peroxidase- and fluorescence-based detection on consecutive sections, respectively. Scale bars: $A-J, 20 \mu \mathrm{m} ; \boldsymbol{K}, \boldsymbol{L}, 100 \mu \mathrm{m}$. $\boldsymbol{M}$, Western blot analysis probing for $\alpha \mathrm{R}$ (Blot: IR) in purified MOE membranes (membrane prep) across various postnatal stages as indicated or in immunoprecipitates (IP: IR) prepared from P20 aged mice; $30 \mu \mathrm{g}$ loaded protein; $M_{\mathrm{r}}=97 \mathrm{kDa}$. $\boldsymbol{N}$, Same as in $\boldsymbol{M}$, but for whole-cell MOE lysates in which varying concentrations of loaded protein (indicated above gel) or donkey anti-rabbit secondary antisera (DAR) (below gel) were tested. Nitrocellulose membranes were cut at the $62 \mathrm{kDa}$ migration marker, and the bottom one-half was probed with $\alpha$-actin (blot $\alpha$-actin) to verify successive increases in protein loading. Note: IR expression begins to resolve at $60 \mu \mathrm{g}$ of loaded protein and displays very faint immunoreactivity at lower protein loading using higher secondary antisera concentrations.

related receptor tyrosine kinase, IGF (insulin-like growth factor) is required for axonal targeting of OR-specific olfactory sensory neurons to lateral glomeruli (Scolnick et al., 2008); however, in our study insulin treatment of adult mice did not appear to change the olfactory sensory map or axonal connections. Although it may be highly unlikely that axonal projections might undergo rearrangement in such a short period, other hormones are known to have effects on the development of the epithelium 
and OB (Brunjes and Alberts, 1980; Paternostro and Meisami, 1996). It is not known whether continued insulin IND treatment could induce such characterized anatomical changes observed in the Kv1.3null mice, especially if the duration extended beyond that known for typical olfactory sensory neuronal turnover $(\sim 30$ d) (Graziadei and Monti-Graziadei, 1978); nonetheless, phosphorylation of Kv1.3 that would predict channel suppression (Fadool et al., 2000) was necessary to cause increased olfactory discrimination. The fact that olfactory discrimination was enhanced by insulin IND treatment and not olfactory threshold to a robust extent, may suggest that the anatomical changes of the super-smeller Kv1.3-null mouse (Fadool et al., 2004) drive regulatory mechanisms that control odor threshold as opposed to those that regulate odor discrimination, which appears to be driven more so by block of channel conduction (phosphorylation). This would infer that fine axonal projections and size of the synaptic glomerular organization regulate odor threshold, whereas that of action potential shape and frequency, which is regulated by Kv1.3 in mitral cell neurons, is highly dependent on state-dependent hormonal cues and neuromodulation to regulate

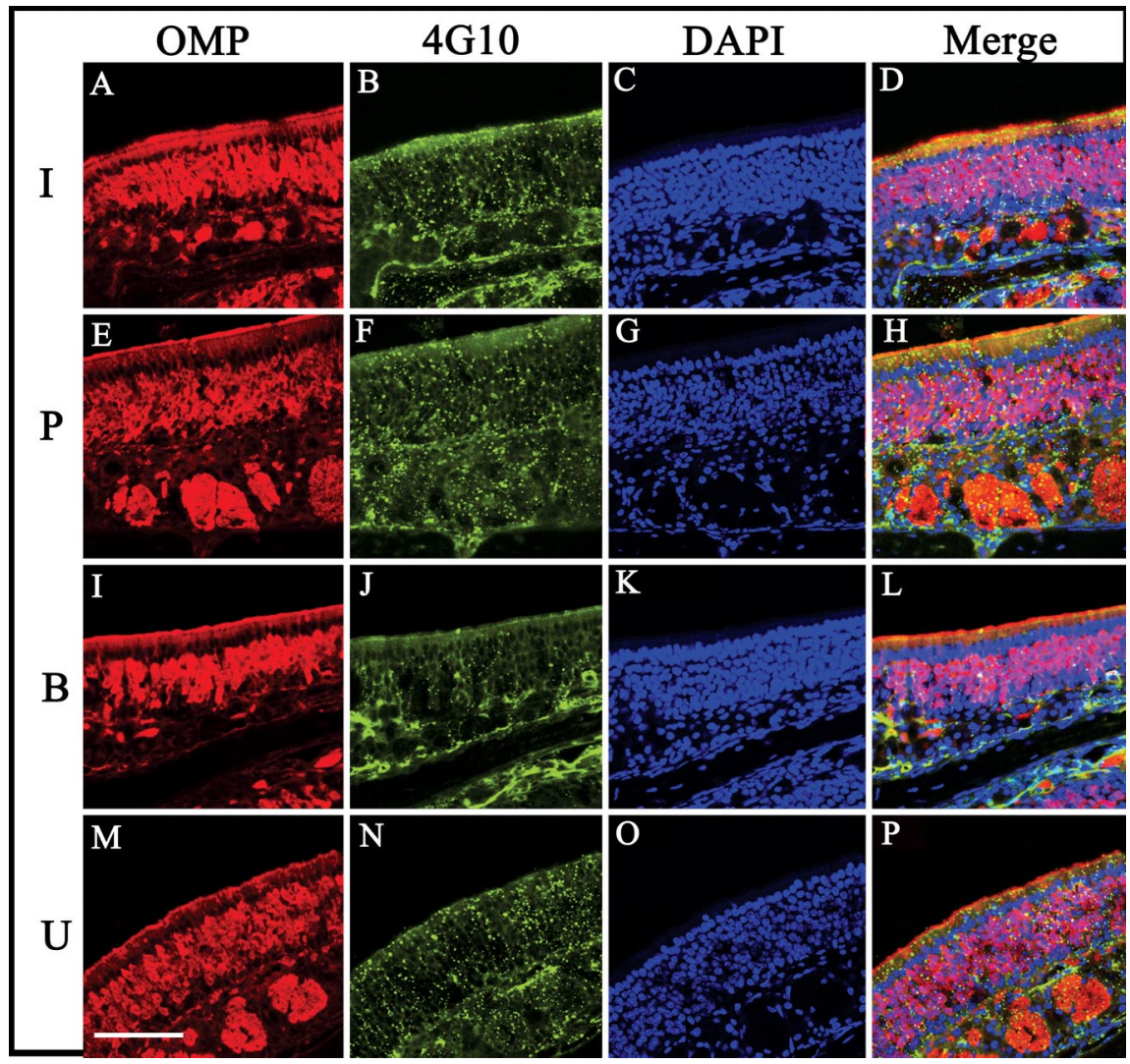

Figure 12. Anti-phosphotyrosine immunoreactivity does not strongly increase after insulin IND treatment. Same as in Figure $10(\boldsymbol{A}-\boldsymbol{P})$ but for anti-phosphotyrosine $(\boldsymbol{B}, \boldsymbol{F}, \boldsymbol{J}, \boldsymbol{N})$. Scale bar, $100 \mu \mathrm{m}$. odor discrimination. Other data presented here also cannot exclude potential insulin effects with the olfactory epithelium, although these would preclude involvement of Kv1.3, which is not expressed in the epithelium (Biju et al., 2008). Leptin and the leptin receptor are expressed with OSN cilia (Getchell et al., 2006; Baly et al., 2007) and are affected by nutritional and metabolic status of the animal. It is therefore entirely possible that insulin and IR within the epithelium could also play a direct role in changes in olfactory discrimination linked with food intake. Nonetheless, insulin IND-treated mice display many of the same behavioral phenotypes as Kv1.3-null mice (Fadool et al., 2004), suggesting that suppression or elimination of OB Kv1.3 current plays a substantial role in our observed behavioral effects.

Our data demonstrating increased short- and long-term object memory in insulin IND-treated mice raises the possibility that insulin also has effects within the hippocampus and is corroborated by strong evidence by others that have found increased declarative memory is enhanced after insulin treatment (Benedict et al., 2004). The fact that insulin fails to increase long-term object memory in our diet-induced obese animals would have important connotations for future therapeutic intervention of memory loss in heavy weight individuals. Sullivan and Wilson (2003) and Satou et al. (2005) hypothesize that some form of olfactory memory may be stored within the $\mathrm{OB}$ via changes in long-term potentiation and changes in synaptic efficacy. Certainly, insulin enhances PSD-95 and IR protein-protein interactions with Kv1.3, suggesting that synaptic scaffolding is altered in response to the hormone.

Most interesting are the observed decreases in anxiety for insulin IND-treated animals. The results of two of three of our anxiety paradigms suggest that obesity modifies the anxiolytic affect of insulin. Behavior of the obese mice in either the LDB or
EPM task is significantly different from that of control fed, insulin IND-treated animals, which infers that obese animals are more anxious when administered insulin than normal mice. To our knowledge, there has been no association between insulin administration and anxiolytic affects in clinical trials or changes in anxiety of diabetic patients beyond the generic effect of increased stress and strain of having a chronic medical condition (Schulingkamp et al., 2000; Delahanty et al., 2007; Mosaku et al., 2008). In fact, subjects receiving IND insulin have reported signs of enhanced mood, reduced anger, and enhanced self-confidence in clinical trials (Benedict et al., 2004), which would be in register with the lack of resistance to handling and treatment that developed in our insulin IND-treated mice. We previously found that prolonged fasting induces a rise in $\mathrm{OB}$ insulin (Fadool et al., 2000). It is possible that, in the fasted state, brain insulin levels rise and produce a reduction in anxiety to facilitate the exploration of novel, unfamiliar, and unusual environments.

The insulin receptor is involved in many signaling cascades and protein-protein interactions beyond the canonical pathways for glucose uptake. Noninvasive routes of insulin delivery have great potential to produce unintentional off-target effects on the olfactory system and the CNS. We found that some of the offtarget effects of CNS-targeted insulin IND include enhanced olfactory discriminatory ability, modified protein-protein interactions, ion channel modulation, as well as enhanced object memory and reduced anxiety. In light of the present data, broad exploration into numerous biochemical signaling changes at the level of the ion channel throughout targeted brain regions needs to be reevaluated. Careful attention must also be placed on examining the consequences of an altered metabolic state (i.e., obesity) 
A

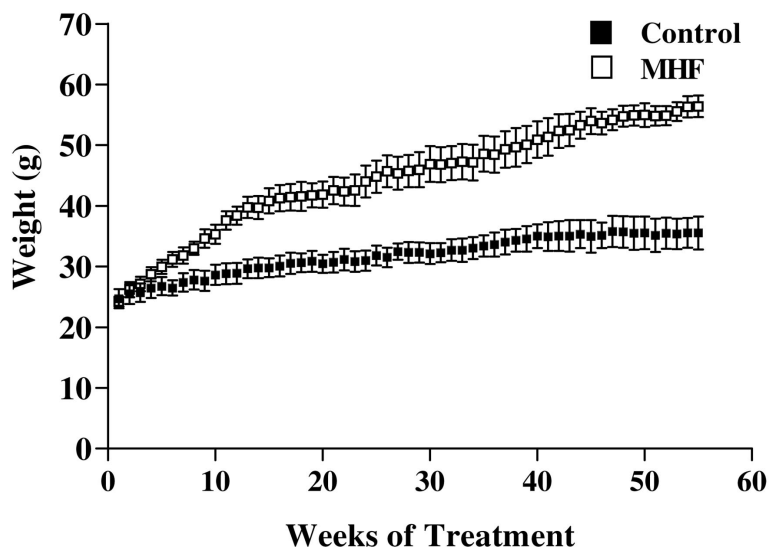

B

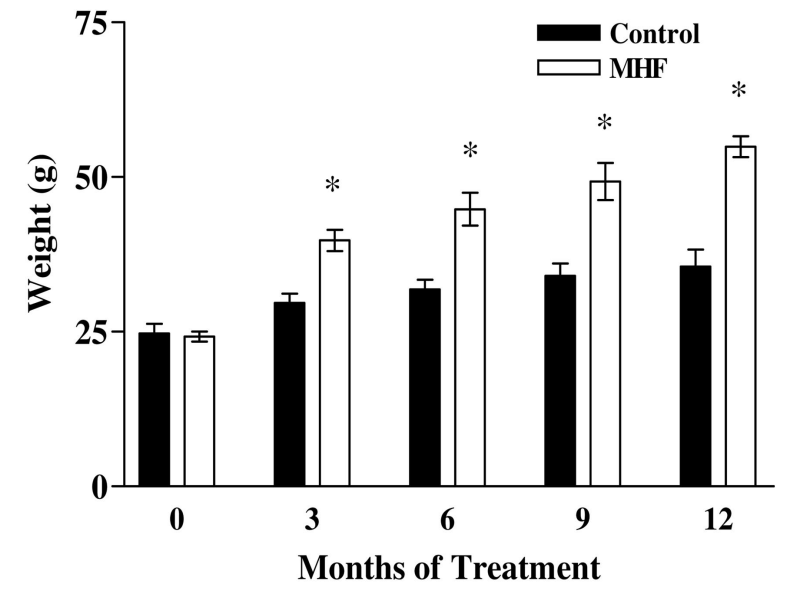

C

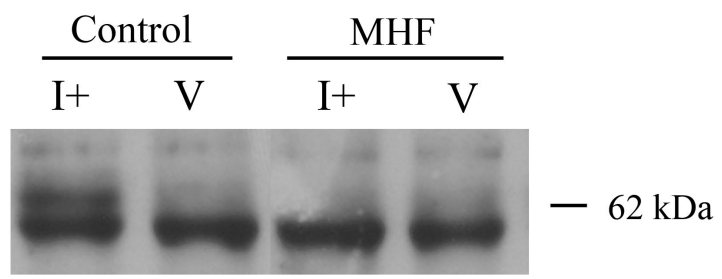

IP: $\quad \mathrm{Kv} 1.3$

Blot: 4G10

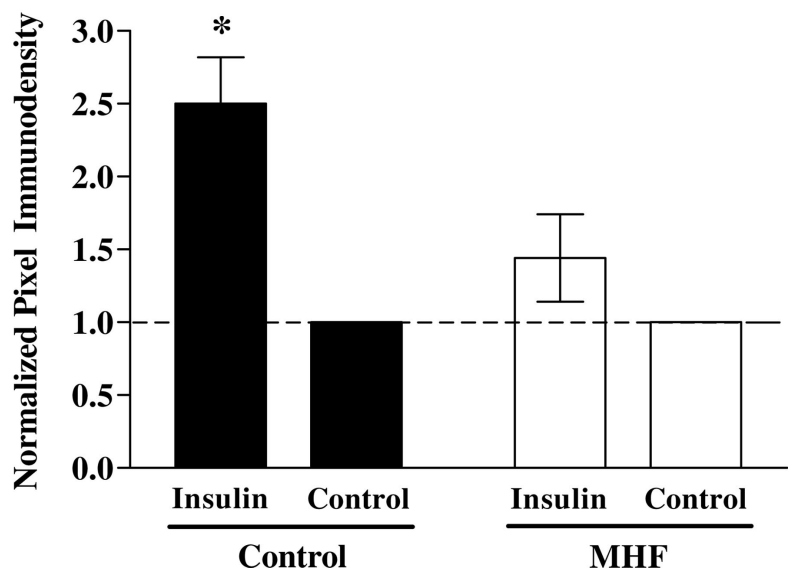

on the efficacy of noninvasive methods of insulin delivery to the CNS.

\section{References}

Aimé P, Duchamp-Viret P, Chaput MA, Savigner A, Mahfouz M, Julliard AK (2007) Fasting increases satiation decreases olfactory detection for a neutral odor in rats. Behav Brain Res 179:258-264.

Apelbaum AF, Chaput MA (2003) Rats habituated to chronic feeding restriction show a smaller increase in olfactory bulb reactivity compared to newly fasted rats. Chem Senses 28:389-395.

Arnold DB, Clapham DE (1999) Molecular determinants for subcellular localization of PSD-95 with an interacting $\mathrm{K}^{+}$channel. Neuron 23:149-157.

Baly C, Aioun J, Badonnel K, Lacroix MC, Durieux D, Schlegel C, Salesse R, Caillol M (2007) Leptin and its receptors are present in the rat olfactory mucosa and modulated by the nutritional status. Brain Res 1129:130-141.

Banks WA (2004) The source of cerebral insulin. Eur J Pharmacol 490:5-12.

Banks WA, Kastin AJ, Pan W (1999) Uptake and degradation of bloodborne insulin by the olfactory bulb. Peptides 20:373-378.

Barnett AH (2004) Exubera inhaled insulin: a review. Int J Clin Pract 58:394-401.

Barry JM, Costall B, Kelly ME, Naylor RJ (1987) Withdrawal syndrome following subchronic treatment with anxiolytic agents. Pharmacol Biochem Behav 27:239-245.

Baskin DG, Porte D Jr, Guest K, Dorsa DM (1983) Regional concentrations of insulin in the rat brain. Endocrinology 112:898-903.

Benedict C, Hallschmid M, Hatke A, Schultes B, Fehm HL, Born J, Kern W (2004) Intranasal insulin improves memory in humans. Psychoneuroendocrinology 29:1326-1334.

Benedict C, Kern W, Schultes B, Born J, Hallschmid M (2008) Differential sensitivity of men and women to anorexigenic and memory-improving effects of intranasal insulin. J Clin Endocrinol Metab 93:1339-1344.

Biju KC, Marks DR, Mast TG, Fadool DA (2008) Deletion of voltage-gated channel affects glomerular refinement and odorant receptor expression in the mouse olfactory system. J Comp Neurol 506:161-179.

Blumstein LK, Crawley JN (1983) Further characterization of a simple, automated exploratory model for the anxiolytic effects of benzodiazepines. Pharmacol Biochem Behav 18:37-40.

Bourin M, Hascoët M (2003) The mouse light/dark box test. Eur J Pharmacol 463:55-65.

Brüning JC, Gautam D, Burks DJ, Gillette J, Schubert M, Orban PC, Klein R, Krone W, Müller-Wieland D, Kahn CR (2000) Role of brain insulin receptor in control of body weight and reproduction. Science 289:2122-2125.

Brunjes PC, Alberts JR (1980) Precocious nasal chemosensitivity in hyperthyroid rat pups. Horm Behav 14:76-85.

Colacicco G, Welzl H, Lipp HP, Würbel H (2002) Attentional set-shifting in mice: modification of a rat paradigm, and evidence for strain-dependent variation. Behav Brain Res 132:95-102.

Colley B, Tucker K, Fadool DA (2004) Comparison of modulation of Kv1.3 channel by two receptor tyrosine kinases in olfactory bulb neurons of rodents. Receptors Channels 10:25-36.

Colley BS, Biju KC, Visegrady A, Campbell S, Fadool DA (2007) Neurotrophin B receptor kinase increases Kv subfamily member 1.3 (Kv1.3) ion channel half-life and surface expression. Neuroscience 144:531-546.

Cook KK, Fadool DA (2002) Two adaptor proteins differentially modulate the phosphorylation and biophysics of Kv1.3 ion channel by Src kinase. J Biol Chem 277:13268-13280.

Craft S, Asthana S, Newcomer JW, Wilkinson CW, Matos IT, Baker LD,

Figure 13. Lack of insulin IND-induced Kv1.3 phosphorylation after maintenance on a MHF diet to yield a prediabetic state. $\boldsymbol{A}, \boldsymbol{B}$, Line $(\boldsymbol{A})$ and bar graph $(\boldsymbol{B})$ plotting the development of body weight gain in control (solid bars) versus MHF diet (open bars) maintained mice for a 55 week period. Data represent the mean ( \pm SEM) of eight mice in each diet treatment group before IND treatment. *Significantly different mean, two-way ANOVA with a Student-Newman-Keuls test $(\alpha=0.05)$. C, Representative Western blot and quantitative scanning densitometry summary bar graph of Kv1.3 tyrosine phosphorylation $(62 \mathrm{kDa})$ in $\mathrm{OB}$ of control and MHF diet fed mice. The bottom band in all conditions is the heavy band of lgG. Analysis, IND treatment interval, and notation are as in Figure 1. 
Cherrier M, Lofgreen C, Latendresse S, Petrova A, Plymate S, Raskind M, Grimwood K, Veith RC (1999) Enhancement of memory in Alzheimer disease with insulin and somatostatin, but not glucose. Arch Gen Psychiatry 56:1135-1140.

Delahanty LM, Grant RW, Wittenberg E, Bosch JL, Wexler DJ, Cagliero E, Meigs JB (2007) Association of diabetes-related emotional distress with diabetes treatment in primary care patients with type 2 diabetes. Diabet Med 24:48-54.

Dhanda DS, Frey WH, Leopold D, Kompella UB (2005) Approaches for drug deposition in the human olfactory epithelium. Drug Delivery Technol 5:64-72.

Dunn C, Curran MP (2006a) Inhaled human insulin (Exubera): a review of its use in adult patients with diabetes mellitus. Drugs 66:1013-1032.

Dunn C, Curran MP (2006b) Spotlight on inhaled human insulin (Exubera) in diabetes mellitus. Treat Endocrinol 5:329-331.

Fadool DA, Levitan IB (1998) Modulation of olfactory bulb neuron potassium current by tyrosine phosphorylation. J Neurosci 18:6126-6137.

Fadool DA, Tucker K, Phillips JJ, Simmen JA (2000) Brain insulin receptor causes activitydependent current suppression in the olfactory bulb through multiple phosphorylation of Kv1.3. J Neurophysiol 83:2332-2348.

Fadool DA, Tucker K, Perkins R, Fasciani G, Thompson RN, Parsons AD, Overton JM, Koni PA, Flavell RA, Kaczmarek LK (2004) Kv1.3 channel gene-targeted deletion produces "super-smeller mice" with altered glomeruli, interacting scaffolding proteins, and biophysics. Neuron 41:389-404.

Fletcher ML, Wilson DA (2002) Experience modifies olfactory acuity: acetylcholinedependent learning decreases behavioral generalization between similar odorants. J Neurosci 22:RC201(1-5).

Gao L, Blair LA, Salinas GD, Needleman LA, Marshall J (2006) Insulin-like growth factor-1 modulation of CaV1.3 calcium channels depends on $\mathrm{Ca}^{2+}$ release from $\mathrm{IP}_{3}$-sensitive stores and calcium/calmodulin kinase II phosphorylation of the $\alpha 1$ subunit EF hand. J Neurosci 26:6259-6268.

Getchell TV, Kwong K, Saunders CP, Stromberg AJ, Getchell ML (2006) Leptin regulates olfactory-mediated behavior in ob/ob mice. Physiol Behav $87: 848-856$.

González C, Kanevsky D, De Marco R, Di Girolamo G, Santoro S (2006) Non-invasive routes for insulin administration: current state and perspectives. Expert Opin Drug Deliv 3:763-770.

Graziadei PPC, Monti-Graziadei GA (1978) Development of sensory systems. In: Handbook of sensory physiology, p 55. Berlin: Springer.

Hallschmid M, Benedict C, Schultes B, Fehm HL, Born J, Kern W (2004) Intranasal insulin reduces body fat in men but not in women. Diabetes 53:3024-3029.

Hallschmid M, Benedict C, Schultes B, Perras B, Fehm HL, Kern W, Born J (2008) Towards the therapeutic use of intranasal neuropeptide administration in metabolic and cognitive disorders. Regul Pept 149:79-83.

Hanson LR, Frey WH 2nd (2007) Strategies for intranasal delivery of therapeutics for the prevention and treatment of neuroAIDS. J Neuroimmune Pharmacol 2:81-86.

Hartman BK, Margolis FL (1975) Immunofluorescence localization of the olfactory marker protein. Brain Res 96:176-180.

Hill JM, Lesniak MA, Pert CB, Roth J (1986) Autoradiographic localization of insulin receptors in rat brain: prominence in olfactory and limbic areas. Neuroscience 17:1127-1136.

Hollander PA (2007) Evolution of a pulmonary insulin delivery system (Exubera) for patients with diabetes. MedGenMed 9:45.

Imaizumi M, Miyazaki S, Machida H (1994a) Discriminative stimulus properties of diazepam and the novel anxiolytic agent 1-amino-5bromouracil in rats. Arzneimittelforschung 44:1105-1107.

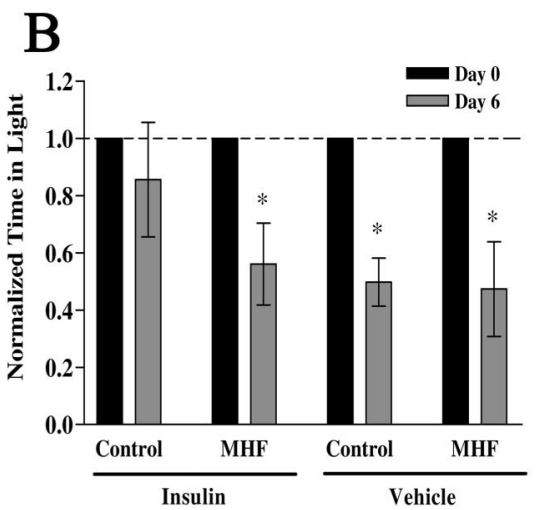

\section{D}

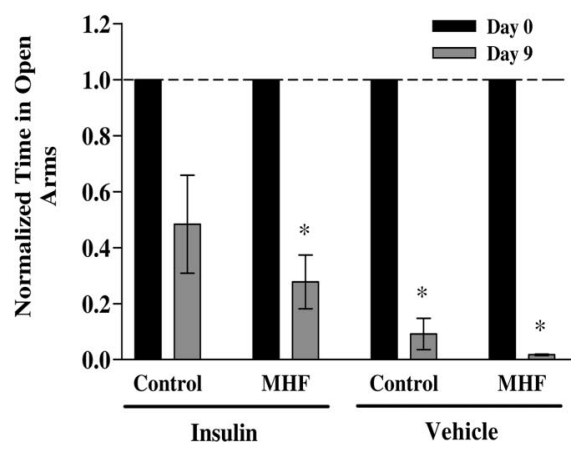

Figure 14. Increased object memory and anxiolytic behaviors after insulin IND treatment is dampened in prediabetic mice. ( $\alpha=0.05, N=2-5$ per treatment group.

Imaizumi M, Miyazaki S, Onodera K (1994b) Effects of xanthine derivatives in a light/dark test in mice and the contribution of adenosine receptors. Methods Exp Clin Pharmacol 16:639-644.

Imaizumi M, Miyazaki S, Onodera K (1994c) Effects of a non-xanthine adenosine antagonist, CGS 15943, and a phosphodiesterase inhibitor, Ro 20-1724, in a light/dark test in mice. Methods Exp Clin Pharmacol 16:717-721.

Jeon D, Yang YM, Jeong MJ, Philipson KD, Rhim H, Shin HS (2003) Enhanced learning and memory in mice lacking $\mathrm{Na}^{+} / \mathrm{Ca}^{2+}$ exchanger 2 . Neuron 38:965-976.

Jones DT, Reed RR (1989) Golf: an olfactory neuron specific-G protein involved in odorant signal transduction. Science 244:790-795.

Julliard AK, Chaput MA, Apelbaum A, Aimé P, Mahfouz M, Duchamp-Viret P (2007) Changes in rat olfactory detection performance induced by orexin and leptin mimicking fasting and satiation. Behav Brain Res 183:123-129.

Kern W, Born J, Schreiber H, Fehm HL (1999) Central nervous system effects of intranasally administered insulin during euglycemia in men. Diabetes 48:557-563.

Khafagy E-S, Morishita M, Onuki Y, Takayama K (2007) Current challenges in non-invasive insulin delivery systems: a comparative review. Adv Drug Delivery Rev 59:1521-1546.

Kim E, Niethammer M, Rothschild A, Jan YN, Sheng M (1995) Clustering of Shaker-type $\mathrm{K}^{+}$channels by interaction with a family of membraneassociated guanylate kinases. Nature 378:85-88.

Lacroix MC, Badonnel K, Meunier N, Tan F, Schlegel-Le Poupon C, Durieux D, Monnerie R, Baly C, Congar P, Salesse R, Caillol M (2008) Expression of insulin system in the olfactory epithelium: first approaches to its role and regulation. J Neuroendocrinol 20:1176-1190.

Lister RG (1987) The use of a plus-maze to measure anxiety in the mouse. Psychopharmacology (Berl) 92:180-185.

Marks DR, Fadool DA (2007) Post-synaptic density perturbs insulin- 
induced Kv1.3 channel modulation via a clustering mechanism involving the SH3 domain. J Neurochem 103:1608-1627.

Matsumoto H, Rhoads DE (1990) Specific binding of insulin to membranes from dendrodendritic synaptosomes of rat olfactory bulb. J Neurochem 54:347-350.

McNay EC (2007) Insulin and ghrelin: peripheral hormones modulating memory and hippocampal function. Curr Opin Pharmacol 7:628-632.

Mombaerts P, Wang F, Dulac C, Chao SK, Nemes A, Mendelsohn M, Edmondson J, Axel R (1996) Visualizing an olfactory sensory map. Cell 87:675-686.

Mosaku K, Kolawole B, Mume C, Ikem R (2008) Depression, anxiety and quality of life among diabetic patients: a comparative study. J Natl Med Assoc 100:73-78.

Neubauer N, Kulkarni RN (2006) Molecular approaches to study control of glucose homeostasis. ILAR J 47:199-211.

Nicolas LB, Kolb Y, Prinssen EP (2006) A combined marble buryinglocomotor activity test in mice: a practical screening test with sensitivity to different classes of anxiolytics and antidepressants. Eur J Pharmacol 547:106-115.

O’Malley D, Harvey J (2007) MAPK-dependent actin cytoskeletal reorganization underlies BK channel activation by insulin. Eur J Neurosci 25:673-682.

Onaivi ES, Martin BR (1989) Neuropharmacological and physiological validation of a computer-controlled two-compartment black and white box for the assessment of anxiety. Prog Neuropsychopharmacol Biol Psychiatry 13:963-976.

Park CR, Seeley RJ, Craft S, Woods SC (2000) Intracerebroventricular insulin enhances memory in a passive-avoidance task. Physiol Behav 68:509-514.

Paternostro MA, Meisami E (1996) Essential role of thyroid hormones in maturation of olfactory receptor neurons: an immunocytochemical study of number and cytoarchitecture of OMP-positive cells in developing rats. Int J Dev Neurosci 14:867-880.

Pellow S, Chopin P, File SE, Briley M (1985) Validation of open:closed arm entries in an elevated plus-maze as a measure of anxiety in the rat. J Neurosci Methods 14:149-167.

Plum L, Schubert M, Brüning JC (2005) The role of insulin receptor signaling in the brain. Trends Endocrinol Metab 16:59-65.

Reagan LP (2007) Insulin signaling effects on memory and mood. Curr Opin Pharmacol 7:633-637.

Reger MA, Craft S (2006) Intranasal insulin administration: a method for dissociating central and peripheral effects of insulin. Drugs Today (Barc) 42:729-739.

Reger MA, Watson GS, Green PS, Wilkinson CW, Baker LD, Cholerton B, Fishel MA, Plymate SR, Breitner JC, DeGroodt W, Mehta P, Craft S (2008) Intranasal insulin improves cognition and modulates 2-amyloid in early AD. Neurology 70:440-448.

Satou M, Anzai S, Huruno M (2005) Long-term potentiation and olfactory memory formation in the carp (Cyprinus carpio L.) olfactory bulb. J Comp Physiol 191:421-434.

Savinger A, Duchamp-Viret P, Grosmaitre X, Chaput M, Garcia S, Ma M,
Palouzier-Paulignan B (2009) Modulation of spontaneous and odorevoked activity of rat olfactory sensory neurons by two anorectic peptides, insulin and leptin. J Neurophysiol. Advance online publication. Retrieved March 18, 2009. doi:10.1152/jn.91169.2008.

Schulingkamp RJ, Pagano TC, Hung D, Raffa RB (2000) Insulin receptors and insulin action in the brain: review and clinical implications. Neurosci Biobehav Rev 24:855-872.

Schwartz MW (2000) Biomedicine. Staying slim with insulin in mind. Science 289:2066-2067.

Scolnick JA, Cui K, Duggan CD, Xuan S, Yuan XB, Efstratiadis A, Ngai J (2008) Role of IGF signaling in olfactory sensory map formation and axon guidance. Neuron 57:847-857.

Shepherd GM (2006) Smell images and the flavour system in the human brain. Nature 444:316-321.

Stevenson RJ, Wilson DA (2007) Odour perception: an object-recognition approach. Perception 36:1821-1833.

Stockhorst U, de Fries D, Steingrueber HJ, Scherbaum WA (2004) Insulin and the CNS: effects on food intake, memory, and endocrine parameters and the role of intranasal insulin administration in humans. Physiol Behav 83:47-54.

Stowe JR, Liu Y, Curtis JT, Freeman ME, Wang Z (2005) Species differences in anxiety-related responses in male prairie and meadow voles: the effects of social isolation. Physiol Behav 86:369-378.

Strachan MWJ (2005) Insulin and cognitive function in humans: experimental data and therapeutic considerations. Biochem Soc Trans 33:1037-1040.

Sullivan RM, Wilson DA (2003) Molecular biology of early olfactory memory. Learn Mem 10:1-4.

Thorne RG, Pronk GJ, Padmanabhan V, Frey WH (2004) Delivery of insulin-like growth factor-I to the rat brain and spinal cord along olfactory and trigeminal pathways following intranasal administration. Neuroscience 127:481-496.

Tucker K, Fadool DA (2002) Neurotrophin modulation of voltage-gated potassium channels in rat through TrkB receptors is time and sensory experience dependent. J Physiol 542:413-429.

Unger J, Moriarty C (2008) Preventing type 2 diabetes. Prim Care 35:645-662.

Van Buren JJ, Bhat S, Rotello R, Pauza ME, Premkumar LS (2005) Sensitization and translocation of TRPV1 by insulin and IGF-I. Mol Pain 1:17.

Wickelgren I (1998) Cellular neuroscience: tracking insulin to the mind. Science 280:517-519.

Wilson DA, Linster C (2008) Neurobiology of a simple memory. J Neurophysiol 100:2-7.

Yee KK, Wysocki CJ (2001) Odorant exposure increases olfactory sensitivity: olfactory epithelium is implicated. Physiol Behav 72:705-711.

Young WS, Kuhar MJ, Roth J, Brownstein MJ (1980) Radiohistochemical localization of insulin receptors in the adult and developing rat brain. Neuropeptides 1:15-22.

Zheng C, Feinstein P, Bozza T, Rodriguez I, Mombaerts P (2000) Peripheral olfactory projections are differentially affected in mice deficient in a cyclic nucleotide-gated channel subunit. Neuron 26:81-91. 